\title{
A modeling analysis of molecular orientation at interfaces by polarization-dependent sum frequency generation vibrational spectroscopy
}

\author{
Xia Li, Günther Rupprechter * \\ Institute of Materials Chemistry, Technische Universität Wien, 1060 Vienna, Austria
}

\section{A R T I C L E I N F O}

\section{Article history:}

Received 29 January 2019

Accepted 18 March 2019

Published 5 November 2019

\section{Keywords:}

Sum frequency generation

spectroscopy

Surface/interface

Heterogeneous catalysis

Molecular orientation

Refractive index

Incidence angles

Molecular hyperpolarizability ratio

\begin{abstract}
A B S T R A C T
Sum frequency generation (SFG) vibrational spectroscopy has been proven an excellent tool to measure the molecular structures, symmetries and orientations at surfaces/interfaces because of its strong polarization dependence. However, a precise quantitative analysis of SFG spectral intensity and molecular orientation at interfaces must be carefully performed. In this work, we summarized the parameters and factors that are often ignored and illustrated them by evaluating studies of CO adsorption on the (111) facet of platinum (Pt) and palladium (Pd) single crystals at the gas (ultra-high vacuum, UHV)/solid interfaces and methanol (water) adsorption at the air/liquid (solid/liquid) interfaces in the presence of sodium iodide (chloride) salts. To intuitively estimate the influence of incidence angles and refractive indices on the SFG intensity, solely a defined factor of $\left|F_{y y z}\right|$ was discussed, which can be individually separated from the macroscopic second-order non-linear susceptibility $\chi_{y y z}^{(2)}$ term and represents the SSP intensity. Moreover, effects of refractive indices and the molecular hyperpolarizability ratio $(R)$ were discussed in the orientational analysis of interfacial $\mathrm{CO}$ and methanol molecules. When $I_{\mathrm{PPP}} / I_{\mathrm{SSP}}$ was identical, molecules with a larger $R$ had smaller tilting angles $\left(\theta\right.$ ) on $\mathrm{Pt}$ (assuming $\theta<51^{\circ}$ ), and $\mathrm{CO}$ molecules on Pd would tilt much closer to the surface than they did on Pt. A total internal reflection (TIR) geometry enhanced the SFG intensity, but it also amplified the influence of refractive index on SFG intensity at the solid (silica)/liquid interface. The refractive index and R-value had similar influence on the methanol orientation in the presence of sodium iodide salts at air/liquid and solid/liquid interfaces. This work should provide a guideline for analyzing the orientation of molecules with different $R$, which are adsorbed on catalysts or located at liquid interfaces involving changes of refractive indices.
\end{abstract}

(C) 2019, Dalian Institute of Chemical Physics, Chinese Academy of Sciences. Published by Elsevier B.V. All rights reserved.

\section{Introduction}

The adsorption of molecules at solid surfaces is a key step in heterogeneous catalysis. The binding energy of a molecule is frequently determined by temperature-programmed methods, such as temperature-programmed desorption (TPD). Mass spectroscopic (MS) measurements of desorbing species, combined with suitable models (such as the Redhead approximation [1]), allow to even discriminate adsorbed species with different binding energy. However, for the identification of

\footnotetext{
*Corresponding author. Tel: +43-1-58801-165100; E-mail: guenther.rupprechter@tuwien.ac.at

This work was in part supported by the Austrian Science Fund FWF through projects ComCat (I 1041-N28) and DK+ Solids4Fun (W1243) and by TU Wien via the Innovative Project "SFG Spectroscopy". X. Li acknowledges the doctoral candidate Jian Hou at Institute of Chemistry, Chinese Academy of Sciences for providing the picture of experimental setup in Fig. 2c.

DOI: S1872-2067(19)63357-7 | http://www.sciencedirect.com/science/journal/18722067 | Chin. J. Catal., Vol. 40, No. 11, November 2019
} 
their molecular structure and binding sites, temperature-dependent spectroscopic studies are required. Among the methods used are vibrational (infrared (IR) or electron energy loss (EELS)) and electron (X-ray photoelectron) spectroscopies [2].

Apart from the mere binding energy of a molecule, its molecular orientation on the surface, which reveals important information about physical and chemical properties, as well as interactions between the adsorbates and substrates [3], is critical for "activating" it for catalysis. A prime example is ethylene adsorption on noble metal surfaces. Using low energy electron diffraction (LEED) surface crystallography, $\pi$ and di- $\sigma$ bonded $\mathrm{C}_{2} \mathrm{H}_{4}$ and ethylidyne $\mathrm{C}_{2} \mathrm{H}_{3}$ were identified, with their abundance and adsorption sites depending on temperature and type of metal [4-6]. There is also a vast body of work of CO adsorption geometries (e.g. hollow, bridge and on-top CO) and (ordered) structures on (typically) low Miller index single crystal surfaces [7]. Further work induces orientation analysis by near-edge X-ray absorption fine structure (NEXAFS) [8]. One has to confess, however, that most studies were carried out under ultrahigh vacuum (UHV) at cryogenic temperatures, which somewhat limits the transferability of these results to technological conditions.

The analysis of molecular orientation can also be carried out by nonlinear optical sum frequency generation (SFG) vibrational spectroscopy. Due to its surface/interface specificity, it can not only characterize adsorbed species at solid or liquid surfaces/interfaces, but can also distinguish the interfacial molecules from chemically identical species in the bulk (liquid or gas phases).

SFG has already been utilized as a powerful tool to probe the surface molecular structure and orientation of adsorbates on solid surfaces relevant for catalytic reactions, including the adsorption of $\mathrm{CO}$ and NO on single crystals [9-14], metal oxides [12], polycrystalline electrodes [9], and nanoparticles [15], as well as methanol dissociation (e.g. coverage-dependent, aerobic and anaerobic conditions) on $\mathrm{TiO}_{2}[16,17]$. Additionally, two types of formates with tilted and perpendicular orientations, which were formed during the decomposition of formic acid on $\mathrm{Ni}(111)$, had been detected using SFG $[18,19]$. The orientation (i.e. tilting and twist angles) of a ( $\mathrm{CO}_{2}$ reduction) catalyst on single crystal $\mathrm{TiO}_{2}$ [20] and gold slide [21] were also obtained by SFG. Furthermore, SFG can be applied to even more complex liquid surfaces, for instance, electrolyte (inorganic ions) aqueous [22-24] and organic (methanol) solutions [25] and polyelectrolyte aqueous solutions [26]. Additionally, water surfaces with monolayer or bilayers of biomolecules (e.g. lipids, peptides, proteins) [27-31], thermosensitive polymers [32], and zwitterionic polymers [33,34] under the influence of $\mathrm{pH}$, salts and nanoparticles, can be measured as well. These studies are of great importance in the fields of e.g. environmental chemistry or biochemistry. SFG even shows advantages in revealing the molecular orientations of organic ions at the air/water interface [35], the arrangement of polymers (macromolecules) at buried surfaces [36,37], as well as the structure of irregular and complex surfaces of polymers roughened by mechanic grinding [38].
Recent studies at the Dalian Institute of Chemical Physics (DICP) reported that the coverage of (intercalated) CO confined between h-BN and Pt(111) was higher than on open Pt(111) [39]. Comparing molecular structure and orientation on confined and open catalysts would be a challenge for SFG.

Herein, we discuss recent results of molecular orientation analysis of adsorbates at gas/solid, air/liquid and solid/liquid interfaces. The effects of experimental configurations and molecular (interface) properties, which have been not treated in detail so far, are thoroughly examined. After illustrating typical experimental configurations and spectroscopic cells, we discuss the basic SFG theory with a focus on the parameters critical for orientation analysis. Selected case studies are then presented to catch a glimpse of state-of-the-art SFG spectroscopy, providing guidelines for future studies.

\section{Basic theory of SFG}

In a SFG process, two light waves at different frequencies interact in a medium spatially and temporally, and then generate a wave at the sum of their frequencies $[3,40,41]$. Generally, one input beam is tunable in the mid-IR range $\left(\omega_{\mathrm{IR}}\right)$, and the second beam is in the visible range with a fixed frequency ( $\omega$ Vis). As illustrated by the energy level diagram in Fig. 1(a), when the IR beam is tuned through a vibrational resonance of the surface molecules, it induces a vibrational transition from the ground state $(v=0)$ to an excited state (e.g. $v=1)$. Simultaneously, the visible beam induces a transition to a higher-energy virtual state. When the virtual state relaxes, a new light is generated at a sum frequency of two incident optical fields $\left(\omega_{\mathrm{SFG}}=\omega_{\mathrm{IR}}+\omega_{\mathrm{Vis}}\right)$. This can be treated as an IR-single resonant SFG process. By continuously tuning $\omega_{\mathrm{IR}}$ and monitoring the intensity of output SFG, a vibrational spectrum of surface molecules is obtained as a plot of the SFG intensity against IR wavenumber (Fig. 3).

SFG is a second-order nonlinear optical process, which is forbidden under the electric-dipole approximation in the bulk of centrosymmetric media with inversion symmetry. Thus, SFG is surface specific and sensitive since the centrosymmetry is broken at the surface or interface. The SFG intensity ( $I_{\mathrm{SFG}}$ ) is proportional to the square of the effective surface nonlinear

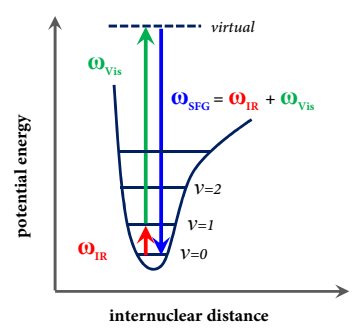

(a)

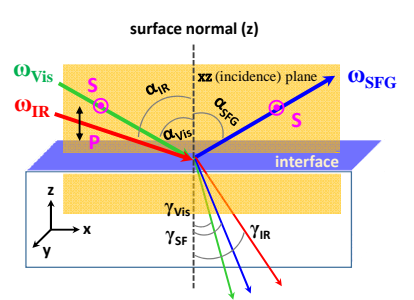

(b)
Fig. 1. (a) Schematic energy level diagram of an IR single-resonance SFG process. (b) Schematic diagram of the definition of angles and polarizations of incident IR, visible and reflected SFG laser beams. Incidence $\left(\alpha_{\mathrm{SFG}}, \alpha_{\mathrm{Vis}}\right.$ and $\left.\alpha_{\mathrm{IR}}\right)$ and refractive $\left(\gamma_{\mathrm{SFG},} \gamma_{\mathrm{Vis}}\right.$ and $\left.\gamma_{\mathrm{IR}}\right)$ angles refer to the angle with respect to the surface normal ( $\mathrm{z}$ axis). $\mathrm{S}$ and $\mathrm{P}$ denote the polarization of the optical field perpendicular to and in the $x z$ (incidence) plane, respectively. 
susceptibility ( $\chi_{\text {eff }}^{(2)}$ ), and the intensities of two incident laser beams $\left(I_{\mathrm{IR}}\right.$ and $\left.I_{\mathrm{Vis}}\right)[40,41]$.

$$
I_{\mathrm{SFG}} \propto\left|\chi_{\mathrm{eff}}^{(2)}\right|^{2} I_{\mathrm{IR}} I_{\mathrm{Vis}}
$$

SFG has polarization dependence, because the laser beams can be switched between $S$ and P polarizations as shown in Fig. 1(b). SSP (SPS, PSS and PPP) polarization combinations are typically written in the order of relative laser energies, i.e. SFG, visible and IR beams. For the co-propagation geometry, i.e. visible and IR beams are incident within the same quarter in the $x z$ plane and SFG signals are collected in a reflected direction (Fig. 1(b)), the polarization-dependent $\chi_{\text {eff }}^{(2)}$ for an achiral and rotationally isotropic interface can be expressed by the macroscopic susceptibilities $\chi_{i j k}^{(2)}$ through [42]:

$$
\begin{aligned}
\chi_{\mathrm{eff}, \mathrm{SSP}}^{(2)}= & L_{y y}\left(\omega_{\mathrm{SFG}}\right) L_{y y}\left(\omega_{\mathrm{Vis}}\right) L_{z z}\left(\omega_{\mathrm{IR}}\right) \sin \alpha_{\mathrm{IR}} \chi_{y y z}^{(2)}=\mathrm{F}_{y y z} \chi_{y y z}^{(2)} \\
\chi_{\mathrm{eff}, \mathrm{SPS}}^{(2)}= & L_{y y}\left(\omega_{\mathrm{SFG}}\right) L_{z z}\left(\omega_{\mathrm{Vis}}\right) L_{y y}\left(\omega_{\mathrm{IR}}\right) \sin \alpha_{\mathrm{Vis}} \chi_{y z y}^{(2)}=\mathrm{F}_{y z y} \chi_{y z y}^{(2)} \\
\chi_{\mathrm{eff}, \mathrm{PSS}}^{(2)}= & L_{z z}\left(\omega_{\mathrm{SFG}}\right) L_{y y}\left(\omega_{\mathrm{Vis}}\right) L_{y y}\left(\omega_{\mathrm{IR}}\right) \sin \alpha_{\mathrm{SFG}} \chi_{z y y}^{(2)}=\mathrm{F}_{z y y} \chi_{z y y}^{(2)} \\
\chi_{\mathrm{eff}, \mathrm{PPP}}^{(2)}= & -L_{x x}\left(\omega_{\mathrm{SFG}}\right) L_{x x}\left(\omega_{\mathrm{Vis}}\right) L_{z z}\left(\omega_{\mathrm{IR}}\right) \cos \alpha_{\mathrm{SFG}} \cos \alpha_{\mathrm{Vis}} \sin \alpha_{\mathrm{IR}} \chi_{x x z}^{(2)} \\
& -L_{x x}\left(\omega_{\mathrm{SFG}}\right) L_{z z}\left(\omega_{\mathrm{Vis}}\right) L_{x x}\left(\omega_{\mathrm{IR}}\right) \cos \alpha_{\mathrm{SFG}} \sin \alpha_{\mathrm{Vis}} \cos \alpha_{\mathrm{IR}} \chi_{x z x}^{(2)} \\
& +L_{z z}\left(\omega_{\mathrm{SFG}}\right) L_{x x}\left(\omega_{\mathrm{Vis}}\right) L_{x x}\left(\omega_{\mathrm{IR}}\right) \sin \alpha_{\mathrm{SFG}} \cos \alpha_{\mathrm{Vis}} \cos \alpha_{\mathrm{IR}} \chi_{z x x}^{(2)} \\
& +L_{z z}\left(\omega_{\mathrm{SFG}}\right) L_{z z}\left(\omega_{\mathrm{Vis}}\right) L_{z z}\left(\omega_{\mathrm{IR}}\right) \sin \alpha_{\mathrm{SFG}} \sin \alpha_{\mathrm{Vis}} \sin \alpha_{\mathrm{IR}} \chi_{\mathrm{zzz}}^{(2)} \\
= & \mathrm{F}_{x x z} \chi_{x x z}^{(2)}+\mathrm{F}_{x z x} \chi_{x z x}^{(2)}+\mathrm{F}_{z x x} \chi_{z x x}^{(2)}+\mathrm{F}_{z z z} \chi_{\mathrm{zzz}}^{(2)}
\end{aligned}
$$

$L_{i i}(i=x, y, z)$ terms are the Fresnel factors for the local field corrections,

$$
\begin{aligned}
L_{x x}\left(\omega_{i}\right) & =\frac{2 n_{1}\left(\omega_{i}\right) \cos \gamma_{i}}{n_{1}\left(\omega_{i}\right) \cos \gamma_{i}+n_{2}\left(\omega_{i}\right) \cos \alpha_{i}} \\
L_{y y}\left(\omega_{i}\right) & =\frac{2 n_{1}\left(\omega_{i}\right) \cos \alpha_{i}}{n_{1}\left(\omega_{i}\right) \cos \alpha_{i}+n_{2}\left(\omega_{i}\right) \cos \gamma_{i}} \\
L_{z z}\left(\omega_{i}\right) & =\frac{2 n_{2}\left(\omega_{i}\right) \cos \alpha_{i}}{n_{2}\left(\omega_{i}\right) \cos \alpha_{i}+n_{1}\left(\omega_{i}\right) \cos \gamma_{i}} \frac{n_{1}^{2}\left(\omega_{i}\right)}{n^{2}\left(\omega_{i}\right)}
\end{aligned}
$$

with $\alpha_{i}$ and $\gamma_{i}$ being the incidence and refraction angles with respect to the surface normal, respectively, for the output SFG, incident visible and IR beams (Fig.1(b)). The laser beam path determines the definition of the interface. $n_{1}\left(\omega_{i}\right), n_{2}\left(\omega_{i}\right)$ and $n^{\prime}\left(\omega_{i}\right)$ are the refractive indices of bulk medium 1 , bulk medium 2 and interfacial layer, respectively. One can see that $L_{i i}$ is a constant when refractive indices, incidence angles $\left(\alpha_{i}\right)$ and refraction angles $\left(\gamma_{i}\right)$ are known.

The values of $n^{\prime}\left(\omega_{i}\right)$ are usually difficult to measure. Herein, they were estimated by the modified Lorentz model, which is usually used for the three-layer model [41]:

$$
n^{\prime}\left(\omega_{i}\right)=n_{1}\left(\omega_{i}\right) n_{2}\left(\omega_{i}\right) \sqrt{\frac{6+n_{2}\left(\omega_{i}\right)^{2}-n_{1}\left(\omega_{i}\right)^{2}}{4 n_{2}\left(\omega_{i}\right)^{2}+2 n_{1}\left(\omega_{i}\right)^{2}}}
$$

$F_{i j k}$ terms contain the coefficients of $L_{i i}$ and cosine/sine of $\alpha_{i}$, which are also constant within certain experimental conditions.

The macroscopic susceptibilities $\chi_{i j k}^{(2)}$ in the laboratory coordinates system $\lambda(\mathrm{x}, \mathrm{y}, \mathrm{z})$ are related to the molecular hyperpolarizability $\beta_{i^{\prime} j^{\prime} k^{\prime}}^{(2)}$ in the molecular coordinates system $\lambda^{\prime}(\mathrm{a}$, b, c) through the Euler transformation [41,42]. For example, the $\chi_{i j k}^{(2)}$ of molecules with $\mathrm{C}_{3 v}$ symmetric stretching (ss) mode (e.g. - $\mathrm{CH}_{3}$ ) simplified by the integration over the twist angle and azimuthal angle of Euler angles can be expressed as:

$$
\begin{aligned}
& \chi_{x x z}^{(2)}=\chi_{y y z}^{(2)}=\frac{1}{2} N_{s} \beta_{c c c}\left[(1+R)\langle\cos \theta\rangle-(1-R)\langle\cos \theta\rangle^{3}\right] \\
& \chi_{x z x}^{(2)}=\chi_{z x x}^{(2)}=\chi_{y z y}^{(2)}=\chi_{z y y}^{(2)}=\frac{1}{2} N_{s} \beta_{c c c}\left[(1-R)\langle\cos \theta\rangle-(1-R)\langle\cos \theta\rangle^{3}\right] \\
& \chi_{z z z}^{(2)}=N_{s} \beta_{c c c}\left[R\langle\cos \theta\rangle+(1-R)\langle\cos \theta\rangle^{3}\right]
\end{aligned}
$$

Where $N_{s}$ is the effective number density of surface molecules, $\theta$ is the tilting angle, which is the angle between the main molecular axis in the molecular coordinates system $\lambda^{\prime}(a, b, c)$ and the $z$ axis in the laboratory coordinates system $\lambda(x, y, z)$ (i.e. the surface normal). The tilting angles of $\mathrm{CO}$ and methanol molecules were defined in Figs. $2 \mathrm{a}$ and $2 \mathrm{~b}$. $\beta_{c c c}$ is the molecular hyperpolarizability, and $R$ is the molecular hyperpolarizability ratio $\left(R=\beta_{a a c} / \beta_{c c c}=\beta_{b b c} / \beta_{c c c}\right)$, which can be calculated by the
CO/Pt(111)
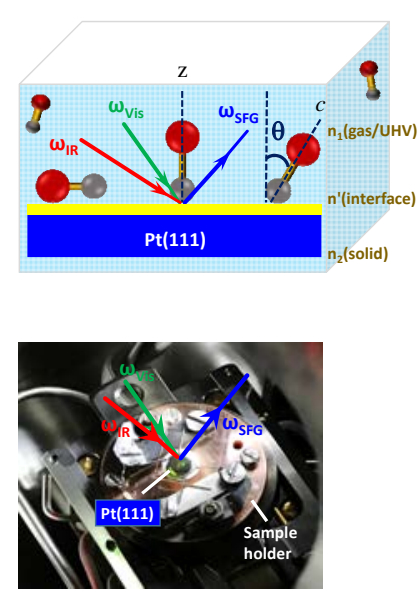

(a) gas (UHV)/solid interface
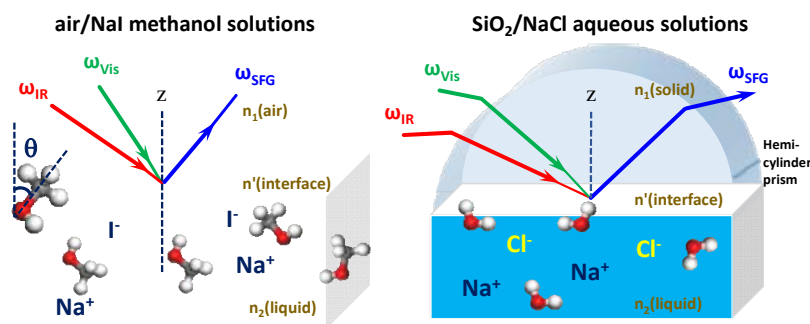

ญ schematic diagram

display of experimental setup

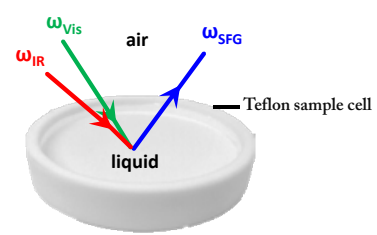

(b) air/liquid interface

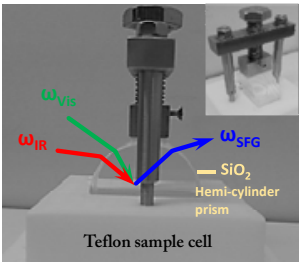

(c) solid/liquid interface

Fig. 2. Schematic diagrams (top panels) and display of experimental SFG setups (bottom panels) of (a) gas (UHV)/solid interface, using CO on Pt(111) as example. (b) Air/liquid interface, using methanol adsorption in the presence of NaI salts at the air/methanol interface as example and (c) solid/liquid interface, using water adsorption in the presence of $\mathrm{NaCl}$ salts at the $\mathrm{SiO}_{2} / \mathrm{H}_{2} \mathrm{O}$ interface as example. The definition of the interface is determined by the laser beam path, for example, the solid/liquid interface in $(c)$ refers to laser beams travelling through the transparent solid phase to the liquid surface. The tilting angle $(\theta)$ is the angle between the main molecular axis in the molecular coordinates system $\lambda^{\prime}(a, b, c)$ and the $z$-axis (surface normal) in the laboratory coordinates system $\lambda(x, y, z)$, e.g. (a) and (b) show the $\theta$ of surface $\mathrm{CO}$ and methanol molecules, respectively. 
Raman depolarization ratio $(\rho)$ [25,42]. For the symmetric stretching modes of $\mathrm{C}_{2 v}$ groups, $R_{a}=\beta_{a a c} / \beta_{c c c} \neq R_{b}=\beta_{b b c} / \beta_{c c c}$ are generally calculated with the bond polarizability derivative model $[43,44]$, but there is still controversy [42]. The expressions of $\chi_{i j k}^{(2)}$ of molecules with a $\mathrm{C}_{\infty v}$ symmetry (e.g. CO) are the same as Eq. (5) with R equal to the bond-polarizability derivative ratio (r) $[41,42,44]$. 〈 > denotes ensemble average over molecular tilting angle. In this paper, a $\delta$-function distribution for tilting angle was assumed in the simulations (modeling).

From Eqs. (2-5), one can see that the $\chi_{\text {eff }}^{(2)}$ of surface molecules depends on the factors of polarizations ( $\mathrm{P}$ or S), laser angles of incident and output beams, refractive indices of two bulk media and their interface, surface number density, orientation and molecular microscopic hyperpolarizability (IR transition dipole moment and Raman polarizability) of molecules. The former three factors are included in the defined $F_{i j k}$ factor, which is a constant under certain experimental conditions. The latter three factors are the intrinsic properties of molecules, which are contained in the macroscopic susceptibility $\chi_{j i k}^{(2)}$. The independence of $F_{i j k}$ and $\chi_{j i k}^{(2)}$ terms will make the following analysis of the effects of incidence angles, refractive indices and R-values on the SFG intensity and molecular orientation much easier.

\section{Experimental}

\subsection{Laser setup}

A picosecond SFG spectrometer (commercial system by EKSPLA [45]) is comprised of three parts: the PL2241 laser, the harmonics unit and the parametric generation/difference frequency generation unit PG501/DFG. The PL2241 laser system, a diode-pumped mode locked neodymium-yttrium-aluminum-garnet (Nd: YAG), generates a fundamental laser beam at $1064 \mathrm{~nm}$ (e.g. $30 \mathrm{ps,} 50 \mathrm{~Hz}, 30 \mathrm{~mJ} /$ pulse), a portion of which is frequency doubled to $532 \mathrm{~nm}$ by a harmonic crystal (deuterated potassium dihydrogen phosphate, $\mathrm{K}^{*} \mathrm{DP}$ ) in the harmonics unit. One part of the $532 \mathrm{~nm}$ beam is directly used as the visible beam for the SFG process. Another part of the $532 \mathrm{~nm}$ beam (max. $10 \mathrm{~mJ}$ ) is used for parametric generator $\mathrm{PG}$, which consists of double-pass $\mathrm{OP}$ generator (OPO) and double-pass OP amplifier (OPA). Tunable signal $(0.68-1.064 \mu \mathrm{m})$ and near-IR idler $(1.064-2.3 \mu \mathrm{m})$ parametric pulses are generated by OPO crystal (BBO-1), diffraction grating (DG) and OPA crystal (BBO-2). Another portion of $1064 \mathrm{~nm}$ (max. $10 \mathrm{~mJ}$ ) and the near-IR idler pulses are spatially and temporally overlapped in a difference frequency generation (DFG) crystal $\left(\mathrm{AgGaS}_{2}\right)$, which generates the tunable mid-IR beam $(2.3-10 \mu \mathrm{m})$ for the SFG process. The polarizations of incident laser beams and of generated SFG signals can be typically adjusted to/collected in S or P polarizations. The SFG signal is detected by a highly sensitive photomultiplier tube (PMT) after passing through optical filters and a monochromator.

As mentioned, SFG measurements can be carried out in any surface/interfaces such as gas (UHV)/solid, air/liquid and solid/liquid interfaces as shown in Fig. 2. Being an excellent surface-specific spectroscopy, SFG has already provided molecular information for many gas or liquid phases, and in ultra-high vacuum (UHV) (e.g. Fig. 3). However, some details of the experimental measurements need to be noted before discussing
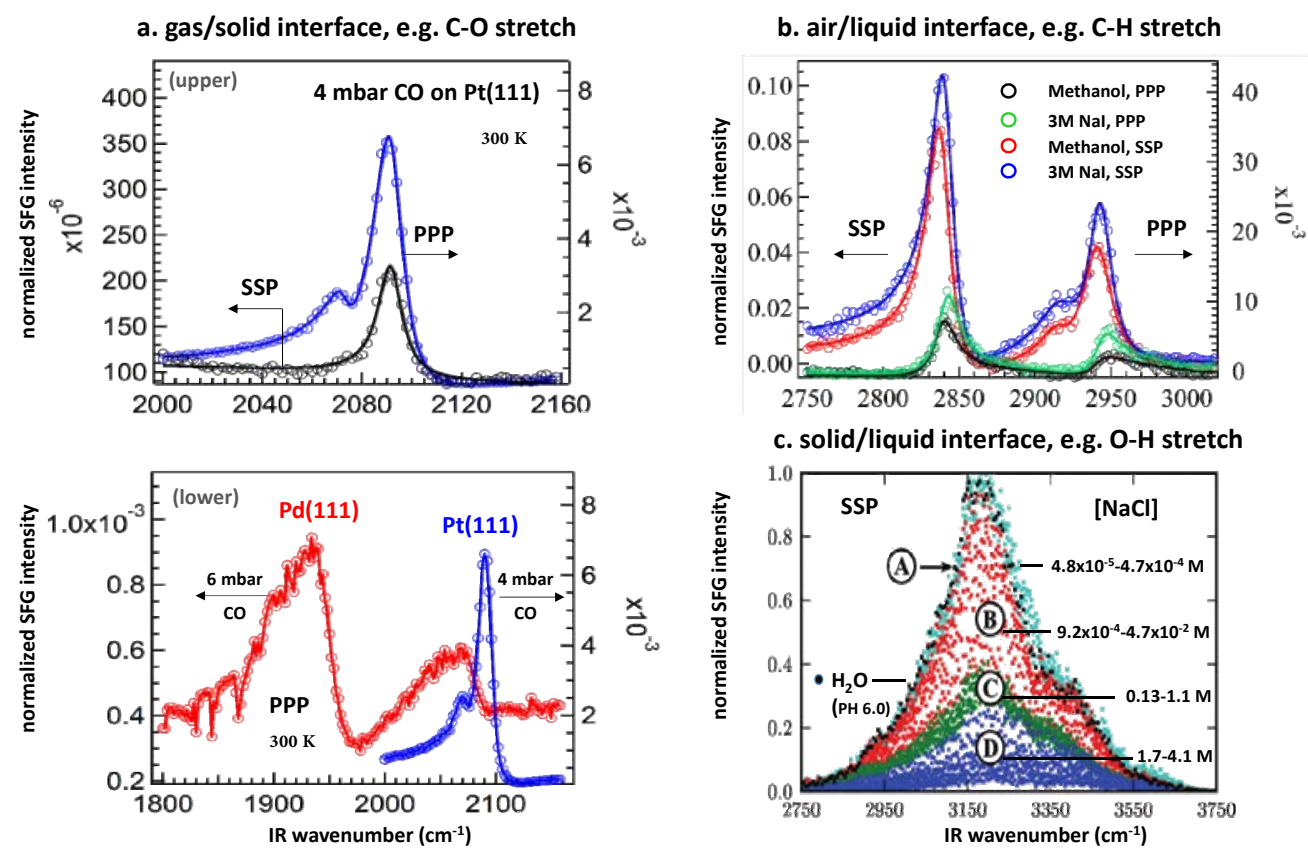

Fig. 3. Selected examples of polarization-dependent SFG spectra of (a) gas/solid interface in the C-O stretching vibration region: SSP and PPP spectra of 4 mbar CO on Pt(111) single crystal (upper panel) and PPP spectra of 6 mbar CO on Pd(111) single crystal (lower panel) at 300 K. Adapted from [11]. (b) air/liquid interface in the C-H stretching vibration region: SSP and PPP spectra of air/methanol interface with and without 3M NaI salts. Adapted from [25]. (c) solid/liquid interface in the $\mathrm{O}-\mathrm{H}$ stretching vibration region: SSP spectra of $\mathrm{SiO}_{2} /$ water interface before and after adding $\mathrm{NaCl}$ salts with a series concentrations. Adapted from [62]. SFG spectra were measured with $\alpha_{\mathrm{Vis}}=58.5^{\circ}, \alpha_{\mathrm{IR}}=55^{\circ} ; \alpha_{\mathrm{Vis}}=45^{\circ}, \alpha_{\mathrm{IR}}=58^{\circ}$ and $\alpha_{\mathrm{Vis}}=66^{\circ}, \alpha_{\mathrm{IR}}=63^{\circ}$ for (a), (b) and (c), respectively. 
results.

\subsection{Gas (UHV)/solid interfaces}

For surface science studies of catalysis, preparing a clean and ordered catalyst surface is typically an important step. Generally, the solid sample (e.g. Pt(111) single crystal) mounted on a dedicated holder (Fig. 2(a)), is inserted into the spectrometer system through a load lock, which is connected to the UHV chamber. Using a magnetic transfer rod, the sample is transferred to the UHV chamber, in which cleaning (e.g. sputter and annealing) and characterization (e.g. LEED, Auger electron spectroscopy (AES)) are performed. Finally, again under UHV, the sample is transferred to the UHV-compatible high pressure SFG cell [46,47], which also allows to introduce gases [48]. For $\mathrm{CO}$, removal of Ni- and Fe-carbonyls by a Cu-based carbonyl scrubber is essential [2]. Generally, $\mathrm{CaF}_{2}$ and quartz windows serve as entrance and exit ports for the incident (IR and visible) laser beams and outlet SFG radiation, respectively. The IR and visible laser beams are overlapped spatially and temporally on e.g. the disk-like $\mathrm{Pt}(111)$ surface (6 mm outer diameter) in a co-propagation geometry to interact with a surface (e.g. CO) molecule, and instantaneously a third beam at the sum of the two frequencies is emitted in the reflection direction as shown in Fig. 2(a). For examples of SFG spectra of CO adsorption on Pt(111), Pd(111) (Fig. 3) and Pt-ZrO $\mathrm{Zr}_{2}$ nanoparticle model catalysts performed in our recently designed SFG system refer to refs $[11,48]$.

\subsection{Air/liquid interfaces}

In a study of air/liquid interfaces, organic contaminations of samples or sample cells have a crucial impact on SFG spectra. For example, the dangling $\mathrm{O}-\mathrm{H}$ stretching of pure water $(\sim 3700$ $\mathrm{cm}^{-1}$ ) disappears in the presence of some organic molecules spreading on the surface. For salt solutions, although some commercial salts contain less than $1 \%$ impurities, e.g. ACS grade or ultrapure grade, trace amounts of organic contaminations still significantly affect the interfacial water spectrum [49]. In order to exclude the unwanted interference of contaminations in salts, salts must be pretreated (e.g. by recrystallization, baking and/or filtration) before use. In addition, any container in touch with the sample must also be clean. Teflon cells, due to high chemical and physical stability as well as corrosion resistance (except XF solutions and molten (strong) alkali (metal)), are good materials for these measurements (Fig. 2(b)). The containers can be cleaned by immersion in freshly prepared Piranha solution (e.g. $\mathrm{H}_{2} \mathrm{SO}_{4}: \mathrm{H}_{2} \mathrm{O}_{2} \approx 3: 1$ volume ratio) for several hours (timing allows to cool down since it is an exothermic reaction), followed by rinsing with conductively pure (Millipore) water $(18.2 \mathrm{M} \Omega \cdot \mathrm{cm})$ [50]. The SFG setup on the optical table is usually covered in a plastic housing to reduce the airflow when measured in air [51].

\subsection{Solid/liquid interfaces}

In an SFG study of solid/gas, solid/liquid and solid/solid in- terfaces, transparent substrates with small non-resonant SFG signals, such as fused quartz $\left(\mathrm{SiO}_{2}\right)$, sapphire $\left(\mathrm{Al}_{2} \mathrm{O}_{3}\right), \mathrm{CaF}_{2}$ and $\mathrm{BaF}_{2}$, in the form of windows or prisms (e.g. hemi-cylinder (Fig. 2(c)), triangular and dome) are usually chosen when designing experiments [37]. However, the chemical stability (e.g. inertness towards liquid phases) and transmission cutoff wavelengths of the selected materials must be carefully considered. For example, $\mathrm{SiO}_{2}$ and $\mathrm{Al}_{2} \mathrm{O}_{3}$ substrates have higher chemical stabilities (e.g. higher hardness and better acid resistance) than $\mathrm{CaF}_{2}$ and $\mathrm{BaF}_{2}$ substrates. The latter may react with some acids (e.g. $\mathrm{H}_{2} \mathrm{SO}_{4}$ ) and even dissolve in water. However, due to the lower transmission cutoff wavelength, $\mathrm{BaF}_{2}\left(770 \mathrm{~cm}^{-1}\right)$ and $\mathrm{CaF}_{2}$ (as low as $1000 \mathrm{~cm}^{-1}$ ) prisms still hold big advantages for studies of low vibrational modes, compared to the cutoff wavelengths of $\mathrm{SiO}_{2} @ 2380 \mathrm{~cm}^{-1}$ and $\mathrm{Al}_{2} \mathrm{O}_{3} @ 2000 \mathrm{~cm}^{-1}$ [37]. One of the setups designed for solid/liquid interfaces, e.g. a $\mathrm{SiO}_{2}$ hemi-cylinder prism in close contact with e.g. $\mathrm{NaCl}$ aqueous solutions (in a Teflon cell) (the entire arrangement held together by a metal bracket), is shown in Fig. 2(c).

\section{SFG spectroscopy at gas/solid, air/liquid and solid/liquid interfaces}

\subsection{CO adsorption on Pt(111) and Pd(111) at gas/solid interfaces}

SFG spectroscopy has been applied to many catalytic processes, including molecular (e.g. $\mathrm{CO}, \mathrm{C}_{2} \mathrm{H}_{4}$ ) adsorption, oxidation and hydrogenation on single crystal surfaces [52,53], (oxide-supported) nanoparticles [54-58], (graphene-supported) nanoclusters [59] and biomimetic crystals [60]. CO was often used as a probe molecule in the research of surface chemistry and catalysis, but most of the SFG studies were carried out in PPP geometry only, which prevents molecular orientation analysis. Recently, SSP and PPP spectra in the C-O stretching vibration region of $\mathrm{CO}$ adsorbed on $\mathrm{Pt}(111)$ at $4 \mathrm{mbar}$ and 300 $\mathrm{K}$ have been obtained [11] and are shown in Fig. 3(a) (upper panel). It is worth noting that the infrared polarization was always kept at $\mathrm{P}$, because an S-polarized: field is canceled on a metal surface [61].

There are two peaks in PPP spectra, both attributed to the linearly bonded CO molecules (i.e. carbon atom bound on top of a single Pt atom, Fig. 4), but adsorbed at different sites of the single crystal surface. The sharp peak at $2092 \mathrm{~cm}^{-1}$ characterizes on-top CO adsorbed on terrace sites, whereas the smaller shoulder at $2073 \mathrm{~cm}^{-1}$ originates from species adsorbed on the step sites (Fig. 4). In turn, the appearance of $2073 \mathrm{~cm}^{-1}$ also reveals the existence of defects (steps or kinks) on Pt(111) crystal. In SSP spectra, only on-top CO at terraces was detectable and the signal was much smaller than that in PPP spectra, while step-sites CO was not observed because of its lower surface number density $\left(\mathrm{N}_{\mathrm{s}}\right)$ [11]. Thus, SFG can not only probe various species adsorbed on different sites of crystals, but also evaluate the smoothness or defectivity of a surface [63,64].

Already two decades ago, Baldelli et al. also reported polarization-dependent SSP and PPP spectra of CO on Pt(111) and polycrystalline $\mathrm{Pt}$ electrodes at different electrode potential. 


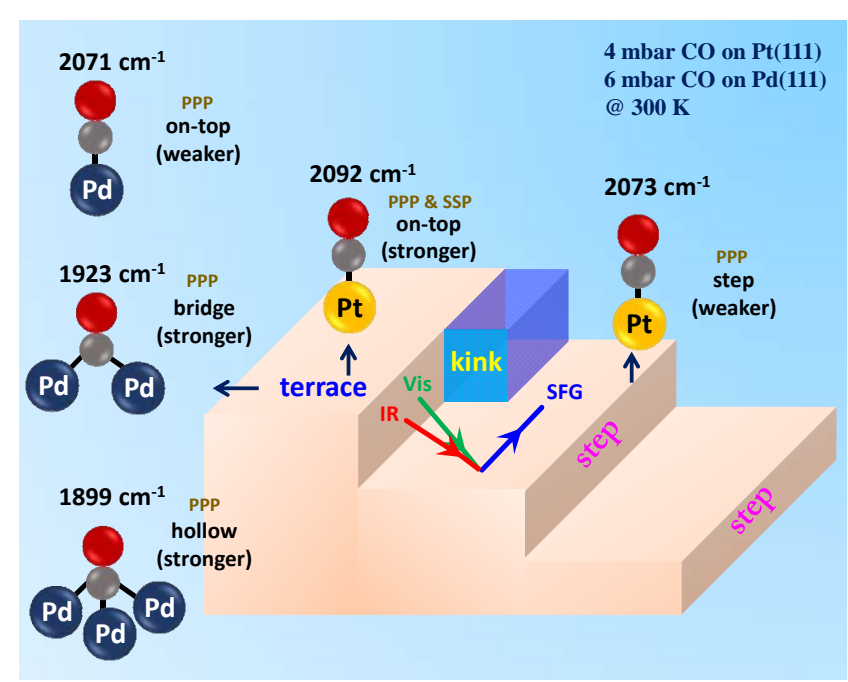

Fig. 4. Schematic diagram of the possible adsorption sites and the corresponding spectral assignments of Fig. 3(a).

Interestingly, for $\mathrm{CO}$ on $\mathrm{Pt}(111)$ single crystal electrode, there was only one peak of on-top CO in PPP spectra, whereas two peaks respectively assigned as three-fold hollow and on-top CO appeared in SSP spectra [9]. Subsequently, SSP, SPS and PPP spectra of CO on PMMA-supported Pt nanoparticle arrays and films were also measured. However, Badelli et al. [15] attributed the difference in these polarization-dependent spectra to the changing dielectric properties of the surface as the Pt coverage increased, rather than probing different orientations of CO, i.e. the orientation information was not deduced for nanoparticles.

Even though the SSP spectral intensity is much smaller than PPP intensity, the spectra still have a good signal-to-noise ratio (Fig. 3(a), upper panel). The intensity ratio ( $\left.I_{\mathrm{PPP}} / I_{\mathrm{SSP}}\right)$ can be utilized to quantitatively calculate the molecular hyperpolarizability ratio $(R)$ or tilting angle $(\theta)$ of CO molecules, and an exact value of $R=0.49$ was previously determined, assuming that the $\mathrm{CO}$ molecules were oriented perpendicular to the surface [11].

However, no SSP signal was obtained for CO on Pd(111) at $300 \mathrm{~K}$. The experimental conditions were the same for $\mathrm{CO}$ on $\operatorname{Pt}(111)\left(I_{S S P_{-}} \mathrm{Pt}(111)<I_{P P P_{-}} \mathrm{Pt}(111)\right)$ and Pd(111) in Fig. 3(a), but their PPP intensities differed largely (IPPP_Pd(111) < IPPP_Pt(111) under similar CO pressure, lower panel). This suggests that the expected SSP intensity of CO on $\mathrm{Pd}(111)$ is also much smaller than that of $\operatorname{Pt}(111)$, and thus difficult to measure (despite simulations indicated nearly equal SSP intensities for Pt and Pd [11]).

In contrast to $\mathrm{Pt}(111)$, on $\mathrm{Pd}(111)$ bridge- (or hollow-) bonded CO (i.e. carbon atom bound to two/three Pd atoms, Fig. 4) at $1923 \mathrm{~cm}^{-1}$ rather than on-top CO at $2071 \mathrm{~cm}^{-1}$ dominated the PPP spectra, accompanied by a small shoulder at lower vibrational frequency $\left(\sim 1899 \mathrm{~cm}^{-1}\right)[2,65]$ as shown in Fig. 3(a) (lower panel). The latter may also indicate hollow-bonded CO.

Distinctly different from $\mathrm{CO}$ on $\operatorname{Pd}(111)$ at $300 \mathrm{~K}\left(\alpha_{\mathrm{Vis}}=\right.$ $\left.58.5^{\circ}, \alpha_{\mathrm{IR}}=55^{\circ}\right)$, Galletto et al. [10] reported that at lower temperature $(90 \mathrm{~K})$ the signal of on-top CO $\left(\alpha_{\mathrm{Vis}}=54^{\circ}, \alpha_{\mathrm{IR}}=56^{\circ}\right)$ dominated in both SSP and PPP spectra, whereas the signals of bridge- and hollow-bonded CO were nearly at the noise level. This spectral difference does not result from the experimental conditions, because similar incidence angles of visible and IR laser beams were employed. However, at lower temperature ( $90 \mathrm{~K}$ ), the higher coverage of $\mathrm{CO}$ molecules and the different cross-section of on top and hollow species [66] explains the SFG spectra at $90 \mathrm{~K}$. Similarly, when coverage decreases and the mobility increases at higher temperature, instead of on top, bridge-bonded CO molecules dominated the PPP spectra at 300 $\mathrm{K}$, with CO preferring to bind two Pd atoms (Fig. 3(a), lower panel).

Furthermore, carbon-based materials, e.g. carbon nanotubes $[67,68]$, graphene-based supercapacitors [69], chemical reaction confined under graphene [70], as well as nanoparticles/nanoclusters deposited on carbon (graphene/HOPG) layer has recently attracted surface scientists $[71,72]$. These studies will provide a new field for the SFG technique, studying more complex catalysts and processes. For instance, SFG has recently performed outstandingly in the study of CO-induced restructuring of Pt nanoclusters grown on graphene [59], as well as of the structure of self-assembled 2D crystal supported on graphene, which was proven to sustain long-lived excitons [60].

\subsection{NaI salt effects on the orientation of methanol molecules at air/liquid interfaces}

Methanol at the air/liquid interface was the first molecule studied by SFG, but only SSP vibrational spectra were obtained [73]. Subsequently, the air/methanol interface was intensively studied as a benchmark interface system, by SFG [25,74-77] and molecular dynamics (MD) simulations [78-81]. These studies were related to the changes of structure (e.g. hydrogen-bonded network), orientation (of methyl group), adsorption isotherm, and the surface enrichment of ions, upon addition of water molecules and salts.

Fig. 3(b) shows the SSP and PPP spectra in the C-H stretching vibration region of air/methanol in the absence and presence of NaI (3M) salts. Three peaks centered at $\sim 2840, \sim 2920$ and $\sim 2940 \mathrm{~cm}^{-1}$ in SSP spectra were assigned to the methyl symmetric stretching $\left(\mathrm{CH}_{3}-\mathrm{SS}\right)$ mode and two Fermi resonance bands of the $\mathrm{CH}_{3}$-SS mode with overtones of the $\mathrm{CH}_{3}$ bending modes [73]. Due to the low surface number density, the Fermi resonance at $2920 \mathrm{~cm}^{-1}$ was at the noise level in PPP spectra. Different from the spectra of CO on $\mathrm{Pt}(111)$, the signal of methanol at the air/methanol interface is much larger in SSP than in PPP. After adding NaI salts (3M), both the SSP and PPP spectral intensities increased. This not only indicated that the interfacial methanol molecules became better ordered, but also confirmed the existence of ions at the interface. The ratio of $I_{\mathrm{SSP}} / I_{\mathrm{PPP}}$ remained almost the same as for pure methanol, meaning an unchanged orientation. However, it was reported that methanol molecules were reoriented by NaI salts, more than $10^{\circ}$ closer to the surface. Moreover, this first demonstrated the importance of refractive indices and Raman depolarizability ratio $\rho$ (hyperpolarizability ratio, R) in the quantitative analysis of SFG spectral intensity and molecular orientation at the air/liquid interface [25]. 


\subsection{NaCl salt effects on the structure of water molecules at solid $\left(\mathrm{SiO}_{2}\right)$ /liquid interfaces}

Water is ubiquitous and the most important liquid on the earth. The understanding of its interfacial properties is crucial for the advances of many disciplines in science and technology. Since Shen and co-workers reported the first vibrational SFG spectrum of the air/water interface in the $\mathrm{O}-\mathrm{H}$ stretching vibration region [82], a vast number of SFG studies emerged, dealing with interfacial structures and orientations of water molecules affected by inorganic ions at the air/liquid [22-24,32,49,83] and solid/liquid $[62,84,85]$ interfaces. These studies focused on the determination of relative surface propensities of ions through the changes of orientation of the "free- $\mathrm{OH}^{\text {" group }}$ (non-hydrogen-bonded, at the top-most layer of air/liquid interface) and the hydrogen bonding of interfacial water molecules. Fig. 3(c) shows the SSP spectra of $\mathrm{O}-\mathrm{H}$ stretch vibrations of the $\mathrm{SiO}_{2}$ /water interface for a series of concentrations of $\mathrm{NaCl}$ salts. Only two broad peaks near 3200 and $3400 \mathrm{~cm}^{-1}$ are observed (because "free- $-\mathrm{OH}^{\prime}$ was terminated by $\mathrm{SiO}_{2}$ ), which are characteristic of interfacial water. They had been assigned to e.g. the ice-like/water-like $[23,82,86]$ or stronger/weaker hydrogen-bonded $\mathrm{OH}$ [87], and donor-bonded $\mathrm{OH}$ of interfacial water with DA, DDA, DAA, or DDAA (D and A refer to donor-and acceptor bonds, respectively, with which a water molecule bound to its neighbors) $[88,89]$. Even though the assignments remain controversial, they certainly originate from the interfacial water molecules more coupled to the bulk phase and are distinct from the top-most layer of the air/water interface [22].

Obviously, the water structures were significantly perturbed upon increasing the ionic strengths, according to the apparent drop of SFG signals in Fig. 3(c). Even though Hore and co-workers [84] later pointed out that both the real and complex parts of refractive indices of $\mathrm{NaCl}$ solutions at 3200 and $3400 \mathrm{~cm}^{-1}$ changed with the concentrations, it was a pity that the influence of changes of refractive indices were not considered in the discussion of disruption of solvent ordering especially at high concentrations. Because a slight increment (1.333 to 1.378) of the refractive indices of bulk solutions result in a significant reduction or disappearance of $I_{\text {SSP }}$ [90].

Since there is no report concerning the effects of incidence angles, refractive indices (bulk substrates or solutions), and hyperpolarizability ratio on the quantitative analysis of SFG spectra at the gas/solid (catalysts), air/liquid and solid/liquid interfaces, an intensity/orientation analysis in light of these factors is presented in the following section.

\section{Quantitative analysis of SFG intensity and orientation at gas/solid, air/liquid and solid/liquid interfaces}

Polarization- and experimental configuration-dependent sum frequency generation (SFG) vibrational spectroscopy is not only an excellent tool for the analysis of structures and orientations of molecules on various surfaces or interfaces, but it can also reveal spectral splitting and the existence of multiple orientations of the interfacial molecules (e.g. [bmim] cations) [50]. However, the changes in the SFG spectra, particularly those of the spectral intensities, must be carefully analyzed because many factors affect them. As discussed in Section 2, the SFG intensity contains contributions of "external" experimental conditions including refractive indices, laser incident angles and polarizations, and "internal" molecular properties, i.e. molecular macroscopic second-order nonlinear susceptibility $\left(\chi_{i j k}^{(2)}\right)$, which is determined by the surface number density (Ns), microscopic hyperpolarizability tensors and average tilting angles $(\theta)$ of surface/interfacial molecules. Unfortunately, in the quantitative analysis of SFG spectra, changes of refractive index of medium $2\left(n_{2}\right)$ and molecular hyperpolarizability ratio (i.e. R-values) were usually ignored, despite having a significant influence on the SFG intensity [90] and orientation [25] analysis, particularly in the study of concentrated salt solutions. Neglecting either the variations of "external" experimental or "internal" molecular factors may lead to misinterpretation of the property of surface molecules.

In the following, we thus separately discuss the influence of (1) incidence angles of visible and IR laser beams ( $\alpha_{\mathrm{IR}}$ and $\alpha_{\mathrm{Vis}}$ ) and bulk refractive indices on the SFG intensity, and of (2) bulk refractive indices and R-values on molecular orientation, at gas/solid, air/liquid and solid/liquid interfaces. $\operatorname{Pt}(111)$, $\mathrm{Pd}(111)$, pure $\mathrm{H}_{2} \mathrm{O}$, pure methanol, $5 \mathrm{M} \mathrm{NaCl}$ aqueous solution and $3 \mathrm{M} \mathrm{NaI}$ methanol solution served as the comparative solid substrates and liquid phases, respectively.

\subsection{Influence of incidence angles of laser beams and refractive indices on the SFG intensity}

The contributions of refractive indices of bulk phases $\left(n_{1}\right.$, $\left.n_{2}\right)$ and interface $\left(n^{\prime}\right)$, laser incident angles and polarizations can be contained in a defined $F_{i j k}$ coefficient, which can be extracted from the $\chi_{i j k}^{(2)}$ item. As shown in Eq. (2), only $F_{y y z}$ is involved in $\chi_{\mathrm{eff}, \mathrm{SSP}}^{(2)}$, therefore, changes of $F_{y y z}$ can be employed to evaluate the influence of refractive indices on SSP spectral intensities due to $\mathrm{I}_{\mathrm{SSP}} \propto\left|\chi_{\mathrm{eff}, \mathrm{SSP}}^{(2)}\right|^{2} \propto\left|F_{\mathrm{yyz}}\right|^{2}$. However, $\chi_{\text {eff, } \mathrm{PPP}}^{(2)}$ is a combination of four $F_{i j k}$ factors $\left(F_{X X Z}, F_{X Z X}, F_{Z X X}\right.$ and $\left.F_{z Z Z}\right)$ and four $\chi_{i j k}^{(2)}$ items, it is thus hard to evaluate the contribution of refractive indices to the PPP intensity on the basis of a single $F_{i j k}$ term, but $F_{z z z}$ was reported to be the dominant factor in PPP, especially when $\alpha_{V i s}$ is close to the critical angles of solid/liquid interfaces [90]. Since $F_{i j k}$ will be a complex number when refractive indices contain imaginary parts (Table 1), the modulus of $F_{i j k}$, i.e. $\left|F_{i j k}\right|$, was adopted in the simulations. Fig. 5 shows the changes of $\left|F_{y y z}\right|$ of gas/solid interface, air/liquid interface and solid/liquid interface as a function of incidence angles. Apparently, proper experimental configuration, i.e. incidence angles $\left(\alpha_{\mathrm{IR}}\right.$ and $\alpha{ }_{\mathrm{Vis}}$ ), plays an important role in obtaining SFG spectra with good signal-to-noise ratio.

For the gas/solid (e.g. Pt) interface $\left(n_{1}=1\right.$, and $\left.n_{1}<n_{2}\right)$ (Fig. 5(a)) and incidence angles ( $\alpha_{\mathrm{IR}}$ and $\left.\alpha_{\mathrm{Vis}}\right)$ smaller than $54^{\circ}$, the values of $\left|F_{y y z}\right|$ at different $\alpha_{\mathrm{Vis}}$ with a fixed $\alpha_{\mathrm{IR}}=55^{\circ}$ (red line) are larger than those at different $\alpha_{\mathrm{IR}}$ with a fixed $\alpha_{\mathrm{Vis}}=55^{\circ}$ (blue line). However, their difference decreases with increasing incidence angles. This is because $\left|F_{y y z}\right|$ increases for $\alpha_{\mathrm{IR}}<73^{\circ}$ but then decreases, while it decreases monotonically with $\alpha_{\text {Vis. }}$. When incidence angles change from $35^{\circ}$ to $65^{\circ}$ (commonly 
Table 1

Refractive indices of media 1 (air, gas, $\mathrm{UHV}$, and $\mathrm{SiO}_{2}$ ) and media 2 ( $\mathrm{Pt}, \mathrm{Pd}, \mathrm{H}_{2} \mathrm{O}$, methanol, $5 \mathrm{M} \mathrm{NaCl}$ aqueous and $3 \mathrm{M}$ NaI methanol solutions) used in the simulations of Figs. 5 and 6 at change to gas (UHV)/solid, air/liquid and solid/liquid interfaces.

\begin{tabular}{|c|c|c|c|c|c|c|}
\hline \multicolumn{7}{|c|}{ gas/solid interface } \\
\hline & $\lambda(\mu \mathrm{m})$ & $n_{1}$ (gas or UHV) & $n_{2}(\mathrm{Pt})[95]$ & $n^{\prime}$ (gas/Pt) & $n_{2}(\mathrm{Pd})[95]$ & $n^{\prime}$ (gas/Pd) \\
\hline Vis & 0.532 & 1 & $2.04+3.6 \mathrm{i}$ & $1.18+1.6 \mathrm{i}$ & $1.60+3.7 \mathrm{i}$ & $0.94+1.6 \mathrm{i}$ \\
\hline SFG & 0.479 & 1 & $1.91+3.3 \mathrm{i}$ & $1.14+1.4 \mathrm{i}$ & $1.47+3.4 \mathrm{i}$ & $0.89+1.4 \mathrm{i}$ \\
\hline IR & 4.785 & 1 & $3.89+18.9 \mathrm{i}$ & $1.96+9.4 \mathrm{i}$ & $3.3+20.2 \mathrm{i}$ & $1.66+10.0 \mathrm{i}$ \\
\hline \multicolumn{7}{|c|}{ air/liquid interface } \\
\hline & $\lambda(\mu \mathrm{m})$ & $n_{1}$ (air) & $n_{2}\left(\mathrm{H}_{2} \mathrm{O}\right)$ & $n^{\prime}\left(\mathrm{air} / \mathrm{H}_{2} \mathrm{O}\right)$ & $n_{2}(5 \mathrm{M} \mathrm{NaCl})$ & $n^{\prime}($ air/5M NaCl) \\
\hline Vis & 0.532 & 1 & $1.333[96]$ & 1.152 & $1.378[97]$ & 1.168 \\
\hline SFG & 0.451 & 1 & 1.337 [96] & 1.15 & 1.378 [97] & 1.168 \\
\hline IR & 2.941 & 1 & $1.264+0.28 \mathrm{i}[98]$ & $1.127+0.117 \mathrm{i}$ & $1.363+0.295 \mathrm{i}[99]$ & $1.167+0.12 \mathrm{i}$ \\
\hline \multicolumn{7}{|c|}{ solid/liquid interface } \\
\hline & $\lambda(\mu \mathrm{m})$ & $n_{1}\left(\mathrm{SiO}_{2}\right)$ & $n_{2}\left(\mathrm{CH}_{3} \mathrm{OH}\right)[25]$ & $n^{\prime}\left(\mathrm{SiO}_{2} / \mathrm{CH}_{3} \mathrm{OH}\right)$ & $n_{2}(3 \mathrm{M} \mathrm{NaI})[25]$ & $n^{\prime}\left(\mathrm{SiO}_{2} / 3 \mathrm{M} \mathrm{NaI}\right)$ \\
\hline Vis & 0.532 & 1.4607 & 1.326 & 0.935 & 1.398 & 0.97 \\
\hline SFG & 0.462 & 1.4647 & 1.326 & 0.934 & 1.398 & 0.968 \\
\hline IR & 3.521 & 1.4053 & 1.326 & 0.962 & 1.398 & 0.997 \\
\hline
\end{tabular}

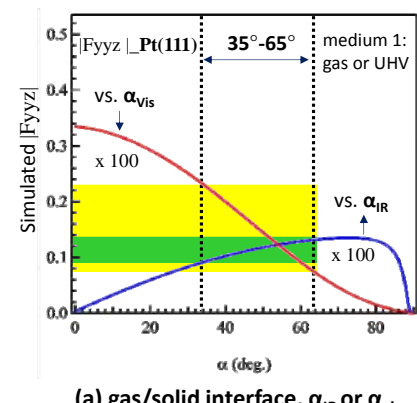

(a) gas/solid interface, $\alpha_{1 R}$ or $\alpha_{\text {vis }}$

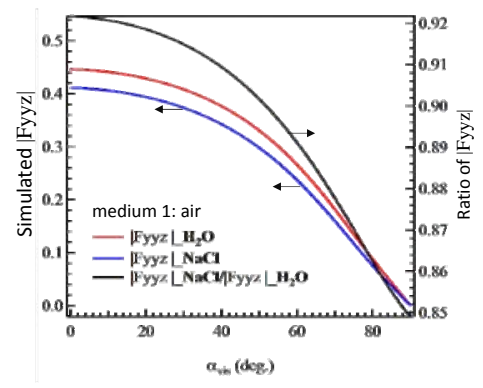

(b) air/liquid interface, $\alpha_{\text {vis }}$

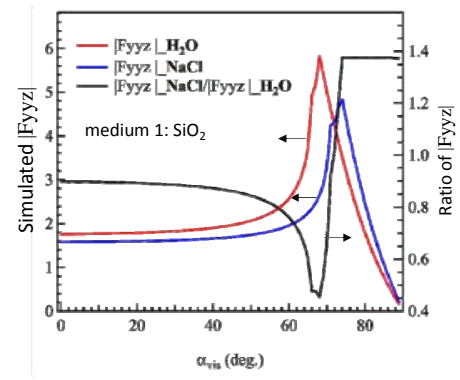

(c) solid/liquid interface, $\alpha_{\text {vis }}$

Fig. 5. (a) Simulated $\left|F_{y y z}\right|$ vs. $\alpha_{\mathrm{Vis}}$ (fixed $\alpha_{\mathrm{IR}}=55^{\circ}$ ) and vs. $\alpha_{\mathrm{IR}}$ (fixed $\alpha_{\mathrm{Vis}}=55^{\circ}$ ) at the gas/solid interface using Pt(111) as exemplary solid substrate, adapted from [11]. (b) Comparing simulated $\left|F_{y y z}\right|$ of $\mathrm{H}_{2} \mathrm{O}$ before and after adding $5 \mathrm{M} \mathrm{NaCl}$ vs. $\alpha_{\mathrm{V} \text { is }}\left(\right.$ fixed $\alpha_{\mathrm{IR}}=58^{\circ}$ ) at the air $/$ liquid interface, (c) Comparing simulated $\left|F_{y y z}\right|$ of $\mathrm{H}_{2} \mathrm{O}$ before and after adding $5 \mathrm{M} \mathrm{NaCl}$ vs. $\alpha_{\mathrm{Vis}}$ (fixed $\alpha_{\mathrm{IR}}=58^{\circ}$ ) at the solid/liquid interface. SiO $\mathrm{O}_{2}$ was chosen as solid substrate. (b) and (c) were adapted from [90].

adopted range), the changes of $\left|F_{y y z}\right|$ to $\alpha_{V i s}$ (yellow band) are almost three times larger than that to $\alpha_{\mathrm{IR}}$ (green band), indicating SSP spectral intensity is much more sensitive to $\alpha_{\mathrm{Vis}}$. Previous studies also indicated the ratio of $I_{\mathrm{PPP}} / I_{\mathrm{SSP}}$ is more sensitive to $\alpha_{V \text { is }}$ [11]. Therefore, only $\left|F_{y y z}\right|$ vs. $\alpha_{V \text { is }}$ with a fixed $\alpha_{\mathrm{IR}}=58^{\circ}$ of the air/liquid and solid/liquid interface are discussed in the following.

For the air/liquid interface $\left(n_{1}=1\right.$, and $\left.n_{1}<n_{2}\right)$, the curve of $\left|F_{y y z}\right|$ vs. $\alpha_{\text {Vis }}$ (Fig. 5(b)) is similar to that of gas (UHV)/solid interface since $\mathrm{n}_{1}$ is identical. However, the values of $\left|F_{y y z}\right|$ decrease significantly because the Fresnel factors decrease with increasing $\mathrm{n}_{2}$. For example, $\left|F_{y y z}\right|_{\text {_Pt }} \mathrm{Pt}$ of gas/solid interface are about two orders of magnitude smaller than $\left|F_{y y z}\right|_{-} \mathrm{H}_{2} \mathrm{O}$ of air/liquid interface (Fig. 5(a) vs. 5(b)) because of $n_{2}(\mathrm{Pt})>n_{2}$ $\left(\mathrm{H}_{2} \mathrm{O}\right)$. However, weak resonant SFG signals can be enhanced by a strong nonresonant background through heterodyne amplification, especially for metals due to their free electrons $[91,92]$. Even though the nonresonant signal can be high and helpful to increase the SFG signal in certain polarization combinations [93], it can also interfere with the resonant signal and result in a distortion of the spectral line shape.

Even a slight increment of $\mathrm{n}_{2}$ at air/liquid interface, e.g. $\sim \mathrm{a}$
$3 \%$ increment of $n_{2}$ (Vis) (i.e. from $1.333\left(\mathrm{H}_{2} \mathrm{O}\right)$ to $1.378(5 \mathrm{M}$ $\mathrm{NaCl}$, i.e.) at room temperature, can cause a $8 \%-15 \%$ decrement of $\left|F_{y y z}\right|$ (black line), which corresponds to a $15 \%-28 \%$ drop of IsSP in the whole range of $\alpha$ vis (black line). Previous SFG studies at air/liquid interfaces, particularly on concentrated salt solutions that involve a non-negligible change in refractive index, should thus be reassessed.

For the solid (e.g. $\left.\mathrm{SiO}_{2}\right)$ /liquid interface $\left(n_{1}>1>n_{2}\right)$ in Fig. 5 (c), which also used water and $5 \mathrm{M} \mathrm{NaCl}$ aqueous as liquid phases (i.e. same $\mathrm{n}_{2}$ as Fig. 5(b)), the values of $\left|F_{y y z}\right|$ are much larger because the Fresnel factors (Eq. 5) are enhanced for bigger $\mathrm{n}_{1}$. This indicates a stronger SFG signal of water at the $\mathrm{SiO}_{2}$ /water interface than at the air/water interface in case of an identical experimental configuration, particularly, when $\alpha_{\mathrm{Vis}}$ is close to the critical angle $\left(\sim 67^{\circ}\right)$ of the total internal reflection (TIR). However, to minimize the IR dispersion, $\alpha_{\text {IR }}$ is suggested to be away from the critical angle if the refractive index of the transmitted or reflected medium is a complex value [94]. Similarly, a significant decrease of $\left|F_{y y z}\right|$ is caused by just a $3 \%$ variation of $\mathrm{n}_{2}$, especially, when $\alpha_{\mathrm{Vis}} \approx 67^{\circ}$, it yielded about $50 \%$ decrement of $\left|F_{y y z}\right|$ (i.e. $75 \%$ drop of ISSP). The SFG intensity is enhanced at higher $\alpha_{V \text { is, }}$ but the influence of refractive index is 
also amplified. Thus, ignoring the changes of refractive index may cause an incorrect interpretation of the molecular property at surfaces/interfaces. For instance, the refractive index of deuterated sulfuric acid $\left(\mathrm{D}_{2} \mathrm{SO}_{4}\right)$ at $20{ }^{\circ} \mathrm{C}$ is 1.423 , thus, the refractive index of $5 \mathrm{M} \mathrm{D}_{2} \mathrm{SO}_{4}-\mathrm{D}_{2} \mathrm{O}$ solutions should be much higher than pure $\mathrm{D}_{2} \mathrm{O}\left(n_{2}=1.33\right)$. The vanished SFG signal at $5 \mathrm{M}$ $\mathrm{D}_{2} \mathrm{SO}_{4} /$ mica surface may not be fully attributed to the reported disappearance of the ordered hydrogen-bonding network [85]. The probable drop of SFG intensity caused by a higher refractive index should also be considered.

Therefore, incidence angles (especially $\alpha_{V \text { is }}$ ) and refractive indices play an important role in the analysis of (SSP-) SFG intensity at interfaces. Particularly, one must be very careful when employing a TIR geometry at solid/liquid interfaces.

\subsection{Influence of refractive index and molecular hyperpolarizability ratio $(R)$ on the molecular orientation}

SFG intensity is a function of higher orders of $\cos \theta$ function (Eq. 5), indicating that it is more sensitive to molecular orientation (tilting angle) than the linear IR and Raman spectroscopies. Besides the refractive indices, the molecular hyperpolarizability ratio $(R)$ of solutions is also strongly changed in the presence of salts. For example, the value of $R$ is 1.7 for the $\mathrm{CH}_{3}$-SS group of pure methanol [42], while it is 2.0 in the presence of $3 \mathrm{M} \mathrm{NaI}$ [25]. To calculate the precise orientation angle, non-negligible changes of these factors should be carefully taken into account.

As discussed above, slight changes of refractive index have a great effect on the SFG intensity, thus it may also affect orienta-

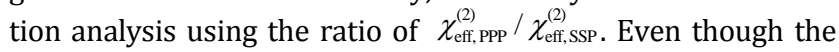
$n_{2}\left(\omega_{\mathrm{IR}}\right)$ and $n^{\prime}\left(\omega_{\mathrm{IR}}\right)$ should vary significantly across the spectral region because of the dispersion, their influence on the orientation analysis will not be significant. Because $\omega_{\mathrm{SFG}}$ and $\omega_{\mathrm{Vis}}$ are not in resonance with the interfacial molecules, $\chi_{x z x}^{(2)}=\chi_{z x x}^{(2)}$ is generally valid [42]. Moreover, $\omega$ SFG is much closer to $\omega$ Vis, the $\chi_{x z}^{(2)}$ and $\chi_{z x x}^{(2)}$ terms of $\chi_{\text {eff, }}^{(2)}$ can nearly cancel out especially when $\alpha_{\mathrm{IR}}$ and $\alpha_{\mathrm{Vis}}$ are equal, making an insignificant contribution to $\chi_{\text {eff, }}^{(2)}$ with a co-propagating geometry [40]. Thus, only

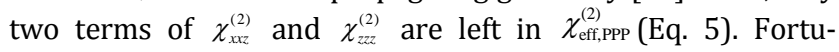
nately, the $n_{2}\left(\omega_{\mathrm{IR}}\right)$ and $n^{\prime}\left(\omega_{\mathrm{IR}}\right)$ only exist in $L_{\mathrm{zz}}\left(\omega_{\mathrm{IR}}\right)$ term (Eq. 3), which can be canceled by the ratio of $\chi_{\text {eff, pPP }}^{(2)} / \chi_{\text {eff, SSP. }}^{(2)}$ However, the contributions of $\chi_{x z x}^{(2)}$ and $\chi_{z x x}^{(2)}$ to $\chi_{\text {eff, }(2)}^{(2)}$ in the counter-propagating geometry are still quite important [42].

Based on Eqs. (2-5), the R-value or tilting angle $(\theta)$ of surface molecules can be therefore determined at certain experimental conditions via the ratio of $\chi_{\mathrm{eff}, \mathrm{PPP}}^{(2)} / \chi_{\mathrm{eff}, \text { SSP }}^{(2)}$ given one of them is known. For instance, the $R$-value $(R=0.49)$ of CO molecules, which can be hardly obtained by Raman depolarizability ratio or the bond polarizability model, can also be deduced from the experimental value of $I_{\mathrm{PPP}} / I_{\mathrm{SSSP}}$, assuming that $\mathrm{CO}$ molecules stand upright on the surface of Pt(111) [11], and vice versa. Similarly, assuming an upright orientation, Baldelli et al. [9] reported the $R$-values (based on the ISSP/IPPP of CO on $\operatorname{Pt}(111)$ electrode) were 0.6 and 1.5 for CO adsorbed on on-top and three-fold hollow sites, respectively. Moreover, a value of 0.1 for the on-top CO on $\operatorname{Pd}(111)$ single crystal at lower gas pressure (10-6 mbar, $0.75 \mathrm{ML})$ and temperature $(90 \mathrm{~K})$ was reported, but it was speculated to change with coverage [10]. Anyway, the non-uniform experimental R-values of adsorbed CO molecules are also quite different from the static hyperpolarizability ratio $(\sim 0.25)$ of the free CO (obtained by DFT calculations) [100], suggesting that the R-value of molecules has a dependence on the substrate, temperature and gas pressure (coverage) if the tilting angles remained unchanged. Nevertheless, previous pressure-dependent SFG spectra of CO on $\mathrm{Pt}(111)$ at $300 \mathrm{~K}$ showed a constant value of $I_{\mathrm{PPP}} / I_{\mathrm{SSP}}$ [11], which would demonstrate an independence of $\mathrm{R}$ on the coverage presuming a constant (upright) orientation of CO molecules.

Fig. 6 shows the influence of R-values and refractive indices ( $n_{1}$ and $n_{2}$ ) on the IppP/IssP as a function of tilting angle $(\theta)$ at gas/solid (CO on Pd vs. Pt single crystals), air/liquid (pure methanol vs. $3 \mathrm{M} \mathrm{NaI}$ ) and solid/liquid (pure methanol vs. 3M $\mathrm{NaI}$ ) interfaces. Most of the refractive indices contain imaginary part (Table 1) so that $\chi^{(2)}{ }_{\text {eff }}$ will also be a complex number, the $I_{\mathrm{PPP}} / I_{\mathrm{SSP}}=\left.\left|\chi_{\text {eff, }}^{(2)}\right|^{2}\right|^{2} /\left.\chi_{\text {eft, sSP }}^{(2)}\right|^{2}$ was therefore used in the simulations. Again, the lineshapes of IPPP/ISSP vs. $\theta$ of gas/solid (Fig. 6(a)) and air/liquid interfaces (Fig. 6(b)) are similar due to an identical $n_{1}$. I IPP $/ I_{\mathrm{SSP}}$ decreases monotonically with increasing $\theta$.

Under identical experimental conditions at the gas/solid interface, molecules with $R=0.30$ (blue line) adsorbing on the $\mathrm{Pt}$ surface, the $I_{\mathrm{PPP}} / I_{\mathrm{SSP}}$ is obviously larger than that of CO molecules ( $R=0.49$ ) on Pt (red line) if $\theta<51^{\circ}$ (Fig. 6(a)). It demonstrates that SSP spectra of molecules having smaller hyperpolarizability ratio $(R)$ or bond-polarizability derivative ratio $(r)$ would be much more difficult to measure in case that their PPP spectral intensities are similar. For example, the $r$ values for C-H group of simple halogenoalkyls and carboxyl acids are in the range of $0-0.25$ [44], and for the free $0 \mathrm{H}$ group of water is about 0.32 [82]. Similarly, CO molecules adsorbing on a Pd surface (which has smaller refractive indices than $\mathrm{Pt}$, Table 1), the larger value of $I_{\mathrm{PPP}} / I_{\mathrm{SSP}}$ (black line) also suggests a weaker SSP signal. This can be confirmed by the experimental result that $I_{\text {SSP }}(\mathrm{Pt})<<I_{\text {PPP }}(\mathrm{Pt})$ (Fig. 3(a)), i.e. SSP intensity is much smaller than PPP, and $I_{\text {PPP }}(\mathrm{Pd})<<$ IPPP (Pt) (Fig. 3(b)), so that IsSP (Pd) should be much smaller than $I_{\mathrm{SSP}}(\mathrm{Pt})$. When $I_{\mathrm{PPP}} / I_{\mathrm{SSP}}=20$, the values of $\theta$ are $24^{\circ}, 36^{\circ}$ and $44^{\circ}$ corresponding to molecules with $R=0.49$ on Pt, $R=0.3$ on Pt and $R=0.49$ on Pd, respectively. These results show that when the $I_{\mathrm{PPP}} / I_{\mathrm{SSP}}$ ratio is identical, molecules with a larger $R$ will have a smaller orientation (tilting) angle on Pt when $\theta<51^{\circ}$. Additionally, CO molecules on Pd would tilt much closer to the surface (larger $\theta$ ) than on Pt.

Furthermore, when the ratio of $I_{\mathrm{PPP}} / I_{\mathrm{SSP}}$ decreases, $\theta$ increases. For example, $I_{\mathrm{PPP}} / I_{\mathrm{SSP}}$ decreases from 20 to 10 , and the tilting angle has an increase of $27^{\circ}, 15^{\circ}$ and $27^{\circ}$ for molecules with $R=0.49$ on $\mathrm{Pt}, R=0.3$ on Pt and $R=0.49$ on Pd, respectively. This indicates that the SFG spectral intensity is more sensitive to the molecular orientation for molecules with a larger hyperpolarizability ratio or bond-polarizability derivative ratio. However, the orientation variations of $\mathrm{CO}$ molecules seem to be independent of the substrates (Pt vs. Pd).

Similarly, the changes of $R$ and refractive index $\left(n_{2}\right)$ of solu- 


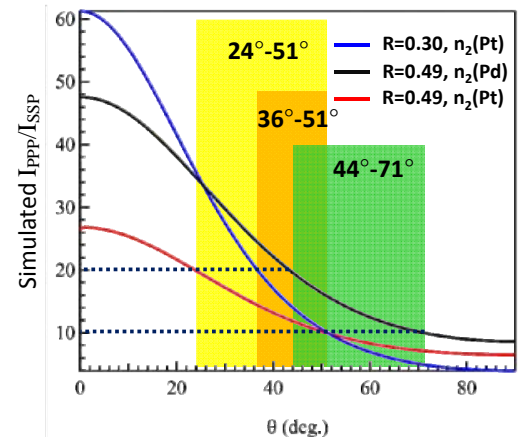

(a) gas/solid interface

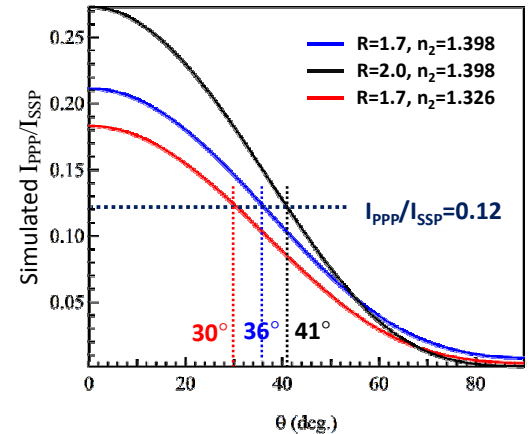

(b) air/liquid interface

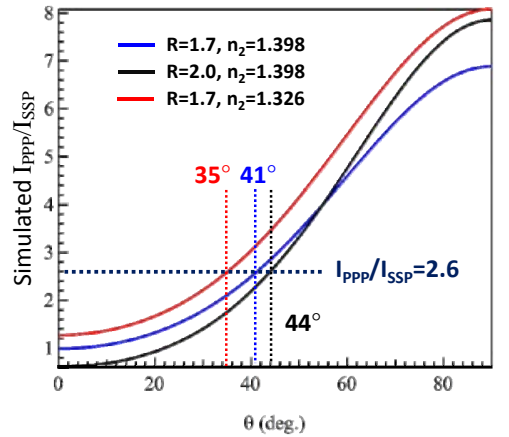

(c) solid/liquid interface

Fig. 6. Simulated $I_{\mathrm{PPP}} / I_{\mathrm{SSP}}$ vs. tilting angle $(\theta)$ for different R values and refractive indices at (a) gas/solid interface, comparing CO molecules adsorbed on the surfaces of $\mathrm{Pt}(111)$ and $\mathrm{Pd}(111)$ single crystals. Adapted from [11]. (b) air/liquid interface. Adapted from [25]. (c) solid/liquid interface. Both (b) and (c) used pure methanol and $3 \mathrm{M} \mathrm{NaI-methanol} \mathrm{solutions} \mathrm{as} \mathrm{examples} \mathrm{of} \mathrm{liquid} \mathrm{phases.} \mathrm{SiO}_{2}$ was chosen as solid substrate in (c). In (a), incidence angles of IR $\left(\omega_{\mathrm{IR}}=2090 \mathrm{~cm}^{-1}\right)$ and visible $\left(\omega_{\mathrm{Vis}}=532 \mathrm{~nm}\right)$ beams were fixed at $\alpha_{\mathrm{IR}}=55^{\circ}, \alpha_{\mathrm{Vis}}=58.5^{\circ}$, respectively. In (b) and (c), incidence angles of IR $\left(\omega_{\mathrm{IR}}=2840 \mathrm{~cm}^{-1}\right)$ and visible $\left(\omega_{\mathrm{Vis}}=532 \mathrm{~nm}\right)$ beams were fixed at $\alpha_{\mathrm{IR}}=58^{\circ}, \alpha_{\mathrm{Vis}}=45^{\circ}$, respectively.

tions at the air/liquid interface should not be ignored either (Fig. 6(b)). As reported before, even though both SSP and PPP spectral intensities of methyl symmetric stretching vibration $\left(\mathrm{CH}_{3}-\mathrm{SS}\right)$ of methanol were obviously enhanced after adding $3 \mathrm{M}$ NaI salts, the ratio of $I$ PPP $/ I_{\text {SSP }}$ (i.e. $\chi_{\mathrm{pPp}}^{(2)} / \chi_{\mathrm{sPp}}^{(2)}=-0.346$ ) was almost identical [25]. This means the tilting angles $\left(\theta=30^{\circ}\right)$ should be unchanged supposing an unchanged value of $R$ and refractive index, i.e. $R=1.7, n_{2}=1.326$ (red line). Unfortunately, both increased in the presence of NaI salts. The tilting angle of air/3M NaI methanol solutions increased to $41^{\circ}$ with $R=2.0$ and $n_{2}=1.398$ (black line), which is over $10^{\circ}$ higher than that of pure methanol. The methanol molecules not only become better ordered (based on the increased SSP and PPP intensity), but they also tilt much closer to the surface under the influence of $3 \mathrm{M} \mathrm{NaI}$ salts [25]. The tilting angle still had a $6^{\circ}$ increase even when only considering the variation of $\mathrm{n}_{2}$ (blue line). The orientation analysis of salt solutions with a constant value of $I_{\mathrm{PPP}} / I_{\mathrm{SSP}}$ should thus be performed carefully. For example, the large difference in refractive index between pure water $(n=$ 1.33) and [bmim][MS] ( $n=1.48)$ (a complex ionic liquid) [51] indicates a strong dependence on the concentration.

Unlike the air/liquid interface, the value of $I_{\mathrm{PPP}} / I_{\mathrm{SSP}}(>1)$ is much bigger and increases with increasing $\theta$ at the solid/liquid interface (Fig. 6(c)). As $\left|F_{y y z}\right|$ (ISSP) is larger at solid/liquid than at air/liquid interface and $I_{\text {PPP }}$ is bigger than IsSP at solid/liquid interface, SFG signals of methanol are stronger at the solid/methanol interface. A constant $\theta=35 \pm 7^{\circ}$ was obtained for all methanol concentrations at octyltrichlorosilane (OTS)-covered $\mathrm{SiO}_{2} /$ methanol-water mixture interfaces [101], which corresponds to $I_{\mathrm{PPP}} / I_{\mathrm{SSP}}=2.6$ (in case that the refractive index of $\mathrm{SiO}_{2}$ was unchanged by the OTS monolayer). Similar to Fig. 6(b), $\theta$ of $3 \mathrm{M} \mathrm{NaI}$ methanol solutions became $44^{\circ}$, which also shows that the methanol molecules at $\mathrm{SiO}_{2}$ /liquid interfaces orient almost $10^{\circ}$ away from the surface normal under the influence of NaI.

Finally, even though the SFG intensity is proportional to the square of molecular surface number density, higher molecular coverage can also lead to some unwanted effects. Previous studies by SFG and DFT predicted a strong dependence of Ra- man activities or non-linear effects on the coverage of adsorbates [66]. The SFG and IR adsorption spectra also indicated a coverage dependence of the Raman tensor involved in the SFG hyperpolarizability tensor [102]. Moreover, a higher coverage of adsorbates on catalysts may destabilize the molecular configuration due to larger repulsive lateral interactions, which would fundamentally change the SFG response [103]. Therefore, any potential changes of factors that influence the SFG spectral analysis must be carefully considered.

\section{Summary and conclusions}

SFG has been proven to be well suited for characterization of interfacial molecules in the $\mathrm{C}-\mathrm{O}, \mathrm{C}-\mathrm{H}$ and $\mathrm{O}-\mathrm{H}$ stretching vibration regions. SFG can not only detect molecules adsorbed at terrace or step sites of single crystals (catalysts) and at liquid interfaces, but it can also evaluate the smoothness or defectivity of catalysts as well as the enrichment/depletion of ions at the interface. An accurate understanding of molecular interfaces depends on the correct interpretation of SFG vibrational spectra, however. Illustrated by examples of CO adsorption on $\mathrm{Pt}(111)$ and $\mathrm{Pd}(111)$ at gas/solid interfaces, NaI salts effects on the methanol orientation at air/liquid interfaces and the influence of $\mathrm{NaCl}$ ionic strength on the disruption of water at solid/liquid interfaces, the analysis of SFG spectral intensity and orientation is illustrated, strongly depending on several parameters and factors. Influences of incidence angles, refractive index and molecular hyperpolarizability ratio $(R)$ on the analysis of SFG intensity and molecular orientation at gas (UHV)/solid, air/liquid and solid/liquid interfaces were separately discussed. When $I_{\mathrm{PPP}} / I_{\mathrm{SSP}}$ is identical, molecules with a larger $R$ will have a smaller orientation angle on Pt (assuming $\theta$ $<51^{\circ}$ ). Moreover, CO molecules on Pd(111) tilt much closer to the surface than on $\operatorname{Pt}\left(111\right.$ ) (for identical $I_{\mathrm{PPP}} / I_{\mathrm{SSP}}$ ). At the gas/solid interface, the changes of orientation are much more sensitive to the molecular $R$ value rather than depend on the type of substrate (Pt vs. Pd). The SFG intensity will be enhanced by a TIR geometry, but the influence of refractive index at solid $\left(\mathrm{SiO}_{2}\right) /$ liquid interface is also increased, much stronger than 
that at the air/liquid interface. In contrast, the refractive index and $R$-value cause similar effects on the orientation of $\mathrm{NaI}$ methanol solutions at air/liquid and solid/liquid interfaces. The analysis of SFG intensity and orientation with a constant value of $I_{\mathrm{PPP}} / I_{\mathrm{SSP}}$ of salt solutions (especially concentrated solutions) must thus be carefully performed.

Conflict of Interest: The authors declare no competing financial or personal relationships with other people or organizations.

\section{Acknowledgments}

This work was in part supported by the Austrian Science Fund FWF through projects ComCat (I 1041-N28) and DK+ Solids4Fun (W1243) and by TU Wien via the Innovative Project "SFG Spectroscopy". X. Li acknowledges the doctoral candidate Jian Hou at Institute of Chemistry, Chinese Academy of Sciences for providing the picture of experimental setup in Fig. 2c.

\section{References}

[1] P. A. Redhead, Vacuum, 1962, 12, 203-211.

[2] G. Rupprechter, Adv. Catal., 2007, 51, 133-263.

[3] Y. R. Shen, Nature, 1989, 337, 519-525.

[4] G. A. Somorjai, G. Rupprechter, J. Phys. Chem. B, 1999, 103, 1623-1638.

[5] G. A. Somorjai, G. Rupprechter, J. Chem. Educ., 1998, 75, 162-176.

[6] G. A. Somorjai, Y. M. Li, Introduction to Surface Science Chemistry and Catalysis, Wiley, New York, 1994

[7] G. Rupprechter, G. A. Somorjai, in: H. P. Bonzel (Ed.), Adsorbed Layers on surfaces. Part 5: Adsorption of molecules on metal, semiconductor and oxide surfaces, Landolt-Börnstein-Group III Condensed Matter, Springer, Berlin, 2006, 243-330.

[8] F. Esch, T. Greber, S. Kennou, A. Siokou, S. Ladas, R. Imbihl, Catal. Lett., 1996, 38, 165-170.
[9] S. Baldelli, N. Markovic, P. Ross, Y. R. Shen, G. Somorjai, J. Phys. Chem. B, 1999, 103, 8920-8925.

[10] P. Galletto, H. Unterhalt, G. Rupprechter, Chem. Phys. Lett., 2003, 367, 785-790.

[11] X. Li, M. Roiaz, V. Pramhaas, C. Rameshan, G. Rupprechter, Top. Catal., 2018, 61, 751-762.

[12] A. Bandara, S. Dobashi, J. Kubota, K. Onda, A. Wada, K. Domen, C. Hirose, S. S. Kano, Surf Sci, 1997, 387, 312-319.

[13] R. Kissel-Osterrieder, F. Behrendt, J. Warnatz, U. Metka, H. R. Volpp, J. Wolfrum, P. Combust. Inst., 2000, 28, 1341-1348.

[14] U. Metka, M. G. Schweitzer, H. R. Volpp, J. Wolfrum, J. Warnatz, Z. Phys. Chem., 2000, 214, 865-888.

[15] S. Baldelli, A. S. Eppler, E. Anderson, Y. R. Shen, G. A. Somorjai, J. Chem. Phys., 2000, 113, 5432-5438.

[16] S. Liu, A. A. Liu, B. Wen, R. D. Zhang, C. Y. Zhou, L. M. Liu, Z. F. Ren, J. Phys. Chem. Lett., 2015, 6, 3327-3334.

[17] R. R. Feng, A. A. Liu, S. Liu, J. J. Shi, R. D. Zhang, Z. F. Ren, J. Phys. Chem. C, 2015, 119, 9798-9804.

[18] A. Bandara, J. Kubota, A. Wada, K. Domen, C. Hirose, Appl. Phys. B, 1999, 68, 573-578.

[19] C. Hirose, A. Bandara, S. Katano, J. Kubota, A. Wada, K. Domen, Appl. Phys. B, 1999, 68, 559-565.

[20] C. L. Anfuso, D. Q. Xiao, A. M. Ricks, C. F. A. Negre, V. S. Batista, T. Q. Lian, J. Phys. Chem. C, 2012, 116, 24107-24114.

[21] Z. G. Li, J. X. Wang, Y. M. Li, W. Xiong, J. Phys. Chem. C, 2016, 120, 20239-20246.

[22] R. R. Feng, Y. Guo, H. F. Wang, J. Chem. Phys., 2014, 141, $18 C 507$.

[23] C. S. Tian, S. J. Byrnes, H. L. Han, Y. R. Shen, J. Phys. Chem. Lett., 2011, 2, 1946-1949.

[24] W. Hua, A. M. Jubb, H. C. Allen, J. Phys. Chem. Lett., 2011, 2, 2515-2520.

[25] X. Li, G. H. Deng, R. J. Feng, K. Lin, Z. Zhang, Y. Bai, Z. Lu, Y. Guo, Chin. Chem. Lett., 2016, 27, 535-539.

[26] F. Schulze-Zachau, S. Bachmann, B. Braunschweig, Langmuir, 2018, 34, 11714-11722.

[27] P. Yang, A. Ramamoorthy, Z. Chen, Langmuir, 2011, 27, 7760-7767.

\section{Graphical Abstract}

Chin. J. Catal., 2019, 40: 1655-1667 doi: S1872-2067(19)63357-7

A modeling analysis of molecular orientation at interfaces by polarization-dependent sum frequency generation vibrational spectroscopy

Xia Li, Günther Rupprechter*

Technische Universität Wien, Austria
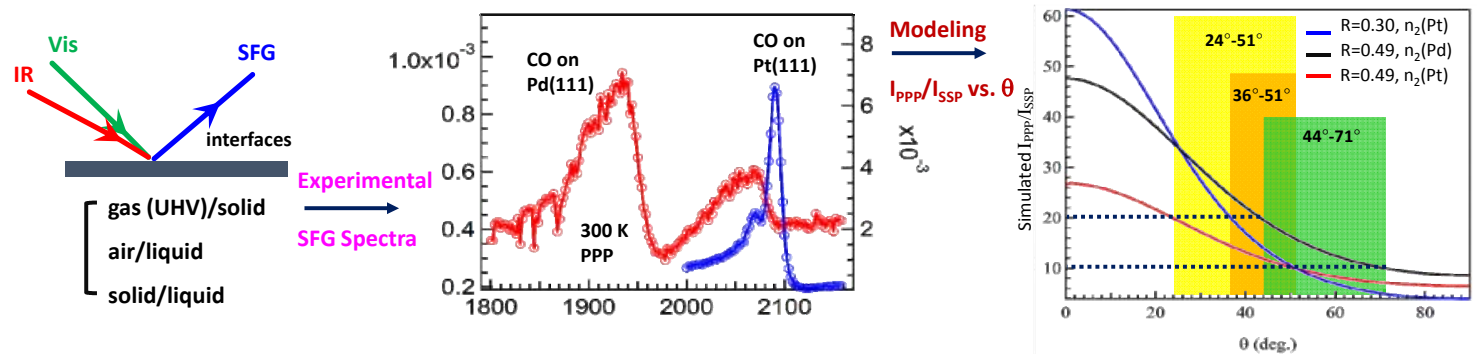

Even slight changes of refractive index (medium 2$)$ and hyperpolarizability ratio $(R=\beta a a c / \beta c c c)$, which are usually rather ignored, have significant effects on the SFG spectral intensity and molecular orientation of gas (UHV)/solid, air/liquid and solid/liquid interfaces. 
[28] F. Wei, S. J. Ye, H. C. Li, Y. Luo, J. Phys. Chem. C, 2013, 117, 11095-11103.

[29] S. J. Ye, F. Wei, H. C. Li, K. Z. Tian, Y. Luo, Adv. Protein Chem. Str., 2013, 93, 213-255.

[30] M. E. Richert, N. Garcia. Rey, B. Braunschweig, J. Phys. Chem. B, 2018, 122, 10377-10383.

[31] P. P. Hu, X. X. Zhang, Y. X. Li, C. Pichan, Z. Chen, Top. Catal., 2018, $61,1148-1162$.

[32] M. Xu, R. Spinney, H. C. Allen, J. Phys. Chem. B, 2009, 113, 4102-4110.

[33] X. F. Han, C. Leng, Q. Shao, S. Y. Jiang, Z. Chen, Langmuir, 2019, 35, 1327-1334.

[34] C. Leng, H. Huang, K. X. Zhang, H. C. Hung, Y. Xu, Y. X. Li, S. Y. Jiang, Z. Chen, Langmuir, 2018, 34, 6538-6545.

[35] S. Strazdaite, J. Versluis, N. Ottosson, H. J. Bakker, J. Phys. Chem. C, 2017, 121, 23398-23405.

[36] I. Chae, S. Ahmed, H. Ben Atitallah, J. W. Luo, Q. Wang, Z. Ounaies, S. H. Kim, Macromolecules, 2017, 50, 2838-2844.

[37] C. Zhang, Appl. Spectrosc., 2017, 71, 1717-1749.

[38] P. Hu, B. Li, C. Bai, X. Li, X. Lu, Anal. Chem., 2018, 90, 14222-14229.

[39] H. Wu, P. J. Ren, P. Zhao, Z. M. Gong, X. D. Wen, Y. Cui, Q. Fu, X. H. Bao, Nano. Res., 2019, 12, 85-90.

[40] X. Wei, S. C. Hong, X. W. Zhuang, T. Goto, Y. R. Shen, Phys. Rev. E, 2000, 62, 5160-5172.

[41] X. Zhuang, P. B. Miranda, D. Kim, Y. R. Shen, Phys. Rev. B, 1999, 59, 12632-12640.

[42] H. F. Wang, W. Gan, R. Lu, Y. Rao, B. H. Wu, Int .Rev. Phys. Chem., 2005, 24, 191-256

[43] C. Hirose, N. Akamatsu, K. Domen, J. Chem. Phys., 1992, 96, 997-1004.

[44] C. Hirose, H. Yamamoto, N. Akamatsu, K. Domen, J. Phys. Chem., 1993, 97, 10064-10069.

[45] Ekspla. SFG spectrometer, in Ekspla Com (Lithuania), SFG Spectrometer Handbooks (PL2241 and PG501/DFG).

[46] G. Rupprechter, Phys. Chem. Chem. Phys., 2001, 3, 4621-4632.

[47] K. Y. Kung, P. Chen, F. Wei, G. Rupprechter, Y. R. Shen, G. A. Somorjai, Rev. Sci. Instrum., 2001, 72, 1806-1809.

[48] M. Roiaz, V. Pramhaas, X. Li, C. Rameshan, G. Rupprechter, Rev. Sci. Instrum., 2018, 89, 045104/1-045104/10.

[49] W. Hua, D. Verreault, E. M. Adams, Z. S. Huang, H. C. Allen, J. Phys. Chem. C, 2013, 117, 19577-19585.

[50] G. H. Deng, Y. Q. Guo, X. Li, Z. Zhang, S. L. Liu, Z. Lu, Y. Guo, Sci. China Chem., 2015, 58, 439-447.

[51] G. H. Deng, X. Li, S. L. Liu, Z. Zhang, Z. Lu, Y. Guo, J. Phys. Chem. C, 2016, 120, 12032-12041.

[52] A. Ouvrard, J. J. Wang, A. Ghalgaoui, S. Nave, S. Carrez, W. Q. Zheng, H. Dubost, B. Bourguignon, J. Phys. Chem. C, 2014, 118, 19688-19700.

[53] X. Li, M. Roiaz, V. Pramhaas, C. Rameshan, G. Rupprechter, Top. Catal., 2018, 61, 751-762.

[54] M. Yang, G. A. Somorjai, J. Phys. Chem. B, 2004, 108, 4405-4410.

[55] A. Ouvrard, A. Ghalgaoui, C. Michel, C. Barth, J. J. Wang, S. Carrez, W. Q. Zheng, C. R. Henry, B. Bourguignon, J. Phys. Chem. C, 2017, $121,5551-5564$.

[56] A. Ghalgaoui, A. Ouvrard, J. J. Wang, S. Carrez, W. Q. Zheng, B. Bourguignon, J. Phys. Chem. Lett., 2017, 8, 2666-2671.

[57] T. Dellwig, J. Hartmann, J. Libuda, I. Meusel, G. Rupprechter, H. Unterhalt, H.-J. Freund, J. Mol. Catal. A, 2000, 162, 51-66.

[58] I. V. Yudanov, R. Sahnoun, K. M. Neyman, N. Rösch, J. Hoffmann, S. Schauermann, V. Johanek, H. Unterhalt, G. Rupprechter, J. Libuda, H.-J. Freund, J. Phys. Chem. B, 2003, 107, 255-264.
[59] N. Podda, M. Corva, F. Mohamed, Z. J. Feng, C. Dri, F. Dvorak, V. Matolin, G. Comelli, M. Peressi, E. Vesselli, ACS Nano., 2017, 11, 1041-1053.

[60] M. Corva, A. Ferrari, M. Rinaldi, Z. Feng, M. Roiaz, C. Rameshan, G. Rupprechter, R. Costantini, M. Dell'Angela, G. Pastore, G. Comelli, N. Seriani, E. Vesselli, Nat. Commun., 2018, 9.

[61] F. M. Hoffmann, Surf. Sci. Rep., 1983, 3, 107-192.

[62] K. C. Jena, P. A. Covert, D. K. Hore, J. Phys. Chem. Lett., 2011, 2 , 1056-1061.

[63] V. V. Kaichev, M. Morkel, H. Unterhalt, I. P. Prosvirin, V. I. Bukhtiyarov, G. Rupprechter, H.-J. Freund, Surf. Sci., 2004, 566-568, 1024-1029.

[64] O. Rodriguez de la Fuente, M. Borasio, P. Galletto, G. Rupprechter, H.-J. Freund, Surf. Sci., 2004, 566, 740-745.

[65] G. Rupprechter, H. Unterhalt, M. Morkel, P. Galletto, L. J. Hu, H.-J. Freund, Surf. Sci., 2002, 502, 109-122.

[66] M. Morkel, H. Unterhalt, T. Klüner, G. Rupprechter, H.-J. Freund, SurfSci., 2005, 586, 146-156.

[67] T. T. Cui, J. H. Dong, X. L. Pan, T. Yu, Q. Fu, X. H. Bao, J. Energy Chem., 2019, 28, 123-127.

[68] X. L. Pan, Z. L. Fan, W. Chen, Y. J. Ding, H. Y. Luo, X. H. Bao, Nat. Mater., 2007, 6, 507-511.

[69] X. Y. Shi, S. H. Zheng, Z. S. Wu, X. H. Bao, J. Energy Chem., 2018, 27, $25-42$.

[70] R. T. Mu, Q. Fu, L. Jin, L. Yu, G. Z. Fang, D. L. Tan, X. H. Bao, Angew. Chem. Int. Ed., 2012, 51, 4856-4859.

[71] A. M. Motin, T. Haunold, A. V. Bukhtiyarov, A. Bera, C. Rameshan, G. Rupprechter, Appl. Surf. Sci., 2018, 440, 680-687.

[72] M. Kettner, C. Stumm, M. Schwarz, C. Schuschke, J. Libuda, Surf. Sci., 2019, 679, 64-73.

[73] R. Superfine, J. Y. Huang, Y. R. Shen, Phys. Rev. Lett., 1991, 66, 1066-1069.

[74] K. Wolfrum, H. Graener, A. Laubereau, Chem. Phys. Lett., 1993, 213, 41-46.

[75] H. Chen, W. Gan, R. Lu, Y. Guo, H.F. Wang, J. Phys. Chem. B, 2005, 109, 8064-8075

[76] G. Ma, H.C. Allen, J. Phys. Chem. B, 2003, 107, 6343-6349.

[77] J. Y. Huang, M. H. Wu, Phys. Rev. E, 1994, 50, 3737-3746.

[78] L. X. Dang, J. Phys. Chem. A, 2004, 108, 9014-9017.

[79] X.Q. Sun, C.D. Wick, L.X. Dang, J. Phys. Chem. A, 2011, 115, 5767-5773.

[80] T. M. Chang, L. X. Dang, J. Phys. Chem. B, 2005, 109, 5759-5765.

[81] T. Ishihara, T. Ishiyama, A. Morita, J. Phys. Chem. C, 2015, 119, 9879-9889.

[82] Q. Du, R. Superfine, E. Freysz, Y.R. Shen, Phys. Rev. Lett., 1993, 70, 2313-2316.

[83] W. Hua, D. Verreault, H. C. Allen, J. Phys. Chem. C, 2014, 118 24941-24949.

[84] P. A. Covert, K. C. Jena, D. K. Hore, J. Phys. Chem. Lett., 2014, 5, 143-148.

[85] Z. Yang, A. K. Bertram, K. C. Chou, J. Phys. Chem. Lett., 2011, 2, 1232-1236.

[86] Y. R. Shen, V. Ostroverkhov, Chem. Rev., 2006, 106, 1140-1154

[87] M. J. Shultz, S. Baldelli, C. Schnitzer, D. Simonelli, J. Phys. Chem. B, 2002, 106, 5313-5324.

[88] D. S. Walker, G. L. Richmond, J. Phys. Chem. C, 2007, 111, 8321-8330.

[89] L. M. Levering, M. R. Sierra-Hernández, H. C. Allen, J. Phys. Chem. C, 2007, 111, 8814-8826.

[90] X. Li, R. J. Feng, J. J. Wang, Z. Zhang, Z. Lu, Y. Guo, Chin. Chem. Lett., 2015, 26, 1542-1546.

[91] J. Wang, X. Y. Chen, M. L. Clarke, Z. Chen, P. Natl. Acad. Sci., 2005, 
102, 4978-4983.

[92] X. L. Lu, N. Shephard, J. L. Han, G. Xue, Z. Chen, Macromolecules, 2008, 41, 8770-8777.

[93] J. Wang, M. L. Clarke, Z. Chen, Anal. Chem., 2004, 76, 2159-2167.

[94] R. L. York, Y. M. Li, G. J. Holinga, G. A. Somorjai, J. Phys. Chem. A, 2009, 113, 2768-2774.

[95] A. D. Rakic, A. B. Djurisic, J. M. Elazar, M. L. Majewski, Appl. Opt., 1998, 37, 5271-5283.

[96] G. M. Hale, M. R. Querry, Appl. Opt., 1973, 12, 555-563.

[97] A. V. Wolf, Aqueous solutions and body fluids; their concentrative properties and conversion tables, Hoeber Medical Division, Harper \& Row, New York, 1966.
[98] D. J. Segelstein, M S, University of Missouri-Kansas City, Kansas City, Missouri, 1981, 1-167.

[99] M. R. Querry, R. C. Waring, W. E. Holland, G. M. Hale, W. Nijm, J. Opt. Soc. Am., 1972, 62, 849-855.

[100] S. J. A. van Gisbergen, J. G. Snijders, E. J. Baerends, J. Chem. Phys., 1998, 109, 10657-10668.

[101] W. T. Liu, L. N. Zhang, Y. R. Shen, J. Chem. Phys., 2006, 125, 144711.

[102] S. Katano, A. Bandara, J. Kubota, K. Onda, A. Wada, K. Domen, C. Hirose, Surf. Sci., 1999, 427-28, 337-342.

[103] V. Pouthier, C. Ramseyer, C. Girardet, J. Chem. Phys., 1998, 108, 6502-6512.

\title{
基于偏振依赖和频振动光谱模拟分析界面分子取向
}

\author{
Xia Li, Günther Rupprechter * \\ 维也纳技术大学材料化学研究所, 1060 维也纳, 奥地利
}

\begin{abstract}
摘要: 和频(SFG)振动光谱由于具有很强的偏振依赖性, 已被证明是测量表面/界面分子结构、对称性和取向的一种很好的 工具. 然而, 对界面上的SFG光谱强度和分子取向的精确定量分析必须仔细地进行. 本本文总结了在分析SFG光谱中常被 忽视的参数和因素, 并通过考察在气体(超高真空, UHV)/固体界面处CO在Pt和Pd单晶(111)面的吸附以及在氯(碘)化钠盐存 在下甲醇(水)在气(固)/液界面上的吸附加以说明其影响. 为了直观地估计激光入射角和介质折射率对SFG强度的影响, 只 讨论了一个定义的因子 $\left|F_{y y z}\right|$, 它可以从宏观二阶非线性磁化率项 $\chi_{y y z}^{(2)}$ 中单独分离出来, 并可代表 SSP强度. 此外, 在界面 $\mathrm{CO}$ 和甲醇分子取向分析中还讨论了折射率和分子超极化率 $(R)$ 的影响. 当 $I_{\mathrm{PPP}} / I_{\mathrm{SSP}}$ 相同时, $R$ 值较大的分子在Pt上的倾斜角 $(\theta)$ 较 小(假设 $\left.\theta<51^{\circ}\right)$, Pd上吸附的CO分子比在Pt上更靠近表面. 全内反射(TIR)几何构型增强了 SFG的强度, 但也放大了折射率 对固 $\left(\mathrm{SiO}_{2}\right)$ 液界面上SFG强度的影响. 在碘化钠作用下, 折射率和R值的变化对甲醇分子在气/液和固/液界面取向的影响相 似. 本文可为分析具有不同 R值的分子在涉及折射率变化的催化剂和液体界面处的取向提供指导.
\end{abstract}

关键词: 和频光谱; 表面/界面; 多相催化; 分子取向; 折射率; 入射角; 分子超极化率

收稿日期: 2019-01-29. 接受日期: 2019-03-18. 出版日期: 2019-11-05.

*通讯联系人. 电话: +43 (1) 58801-165100; 电子信箱: guenther.rupprechter@tuwien.ac.at

本文的电子版全文由Elsevier出版社在ScienceDirect上出版(http://www.sciencedirect.com/science/journal/18722067). 